\title{
Article \\ Superwicking Functionality of Femtosecond Laser Textured Aluminum at High Temperatures
}

\author{
Ranran Fang ${ }^{1}$, Xianhang Zhang ${ }^{1}$, Jiangen Zheng ${ }^{1}$, Zhonglin Pan ${ }^{2}$, Chen Yang ${ }^{2}$, Lianrui Deng ${ }^{2}$, Rui Li ${ }^{3}$, \\ Chunhong Lai ${ }^{1}$, Wensheng Yan ${ }^{1}$, Valeriy S. Maisotsenko ${ }^{4}$ and Anatoliy Y. Vorobyev ${ }^{1, *}$ \\ 1 School of Optoelectronic Engineering, Chongqing University of Posts and Telecommunications, 2 Chongwen Road, \\ Chongqing 400065, China; fangrr@cqupt.edu.cn (R.F.); s190402010@stu.cqupt.edu.cn (X.Z.); \\ zhengjg@cqupt.edu.cn (J.Z.); laich@cqupt.edu.cn (C.L.); yws118@gmail.com (W.Y.) \\ 2 School of Science, Chongqing University of Posts and Telecommunications, 2 Chongwen Road, \\ Chongqing 400065, China; pzl15185309575@163.com (Z.P.); y2379202627@163.com (C.Y.); \\ DLR20010527@163.com (L.D.) \\ 3 School of Automation, Chongqing University of Posts and Telecommunications, 2 Chongwen Road, \\ Chongqing 400065, China; lirui@cqupt.edu.cn \\ 4 M-Cycle Corporation, 1120 Delaware St. \#110, Denver, CO 80204, USA; valeriymaisotsenko@gmail.com \\ * Correspondence: ayv@cqupt.edu.cn
}

\section{check for} updates

Citation: Fang, R.; Zhang, X.; Zheng, J.; Pan, Z.; Yang, C.; Deng, L.; Li, R.; Lai, C.; Yan, W.; Maisotsenko, V.S.; et al. Superwicking Functionality of Femtosecond Laser Textured Aluminum at High Temperatures. Nanomaterials 2021, 11, 2964. https:// doi.org/10.3390/nano11112964

Academic Editors: Florenta Costache, Stéphane Valette, Jörn Bonse and Ion N. Mihailescu

Received: 14 September 2021 Accepted: 1 November 2021 Published: 4 November 2021

Publisher's Note: MDPI stays neutral with regard to jurisdictional claims in published maps and institutional affiliations.

Copyright: (C) 2021 by the authors Licensee MDPI, Basel, Switzerland. This article is an open access article distributed under the terms and conditions of the Creative Commons Attribution (CC BY) license (https:/ / creativecommons.org/licenses/by/ $4.0 /)$.

\begin{abstract}
An advanced superwicking aluminum material based on a microgroove surface structure textured with both laser-induced periodic surface structures and fine microholes was produced by direct femtosecond laser nano/microstructuring technology. The created material demonstrates excellent wicking performance in a temperature range of 23 to $120^{\circ} \mathrm{C}$. The experiments on wicking dynamics show a record-high velocity of water spreading that achieves about $450 \mathrm{~mm} / \mathrm{s}$ at $23^{\circ} \mathrm{C}$ and $320 \mathrm{~mm} / \mathrm{s}$ at $120^{\circ} \mathrm{C}$ when the spreading water undergoes intensive boiling. The lifetime of classic Washburn capillary flow dynamics shortens as the temperature increases up to $80^{\circ} \mathrm{C}$. The effects of evaporation and boiling on water spreading become significant above $80^{\circ} \mathrm{C}$, resulting in vanishing of Washburn's dynamics. Both the inertial and visco-inertial flow regimes are insignificantly affected by evaporation at temperatures below the boiling point of water. The boiling effect on the inertial regime is small at $120^{\circ} \mathrm{C}$; however, its effect on the visco-inertial regime is essential. The created material with effective wicking performance under water boiling conditions can find applications in Maisotsenko cycle (M-cycle) high-temperature heat/mass exchangers for enhancing power generation efficiency that is an important factor in reducing $\mathrm{CO}_{2}$ emissions and mitigation of the global climate change.
\end{abstract}

Keywords: wicking materials; aluminum; femtosecond laser processing; nanostructures; microstructures; laser-induced periodic surface structures (LIPSS); capillarity flow dynamics; cooling of electronics; Maisotsenko cycle; global climate change

\section{Introduction}

Commonly, the direct laser ablation method produces wicking materials with hierarchical capillary structures composed of a basic microstructure (typically, microgrooves or micropillars) and a random fine micro/nanotexture on the surface of the basic microstructure [1]. The hierarchical property of the laser-produced capillary structures comes from the nature of direct femtosecond laser ablation that intrinsically induces random surface structures on nano- and micro-scales [2-10]. Previous studies have been mainly focused on the optimization of the basic capillary microstructures with random nano/microtextures [1,11-18]. In addition to the random nano/microtextures, the direct laser ablation also allows producing regular surface nano/microstructures (referred to as laser-induced periodic surface structures (LIPSS) or ripples) through surface plasmon polariton or some sort of self-organization mechanisms [1,19-41]. LIPSSs have found many applications in the modification of the optical [42-52], wetting [53,54], 
biomedical [55-58], catalytic [59], tribological [60], superconducting [61], and other [62,63] properties of materials. Recently, it has been demonstrated that LIPSSs produced on the surface of micropillars and microholes enhance the wicking functionality of a micropillar/microhole array structure fabricated by direct femtosecond laser writing on a Ti-6Al-4V alloy surface [64]. Here, we apply the LIPSS texturing approach to enhance the capillary action of an array of parallel microgrooves on aluminum. In addition to LIPSSs, we also produce random fine microholes on the ridges and valleys of the microgrooves for improving the stability of the capillary performance at high temperatures. These fine microholes play the role of microreservoirs, supplying water to areas with intensive evaporation and preventing dry-out spot formation in cooling applications. Our research on efficient wicking materials is motivated by a large variety of their applications in such areas as the thermal management of high-heat flux semiconductor electronics [65], cooling data centers [66,67], energy-harvesting [68], thermal management of robots [69], water desalination [18,70], waste heat recovery [71-73], spacecraft thermal management [74,75], and Maisotsenko cycle (M-cycle) technologies [76-79]. Our choice of aluminum is stimulated by its longterm stable wicking properties due to the formation of a hydrophilic aluminum oxide hydroxide $[\gamma-\mathrm{AlO}(\mathrm{OH})]$ surface layer (referred to as the Boehmite layer) caused by the chemical interaction of aluminum with hot water that improves both the hydrophilic and corrosion-resistance properties of Al wicks [80-83]. Previously, capillary flow dynamics in microgrooves produced on an aluminum surface by femtosecond laser pulses has been studied at the stage of the classic Washburn flow at room temperature $[15,16,18]$. However, many important applications require materials with efficient wicking functionality at high temperatures. In this paper, we study the wicking performance of our material in a temperature range between 23 and $120^{\circ} \mathrm{C}$. Furthermore, our study of the capillary flow dynamics includes the inertial and visco-inertial stages occurring prior to Washburn's regime of liquid spreading. Understanding the capillary flow in the initial stages is important for preventing dry-out spots in cooling high-heat flux electronic devices of $4 \mathrm{G} / 5 \mathrm{G}$ telecom networks [65] and in designing miniature lab-on-chips, where the length of the capillary channel is so small that the Washburn stage does not take place [84].

The results of our study on capillary water spreading dynamics show that the created array of microgrooves with both LIPSS and fine microhole textures provides a record-high velocity of water transport, reaching about $450-500 \mathrm{~mm} / \mathrm{s}$ in the inertial stage of capillary flow; for a comparison, the highest water spreading velocity of $370 \mathrm{~mm} / \mathrm{s}$ in capillary microgrooves has been previously reported in [85]. Even at $120^{\circ} \mathrm{C}$, when the spreading water intensively boils, the maximum capillary flow velocity remains extraordinarily high, achieving about $320 \mathrm{~mm} / \mathrm{s}$. The developed hierarchical wicking material outperforms the other reported materials in terms of the wicking performance in a wide temperature range, indicating its practical potential for a broad range of applications mentioned above. An important issue is that applications of the created material in M-cycle technologies for air-conditioning and power generation sectors can essentially increase energy efficiency in these sectors, thus reducing greenhouse gas emissions and contributing to the mitigation of the global climate change.

\section{Experimental Section: Fabrication and Characterization}

The capillary 1D array of parallel microgrooves on the surface of aluminum is produced using a femtosecond laser system (Astrella, Coherent Inc., Santa Clara, CA, USA) that generates $86 \mathrm{fs}$ pulses with energy of $7.13 \mathrm{~mJ} /$ pulse at a maximum repetition rate of $1 \mathrm{kHz}$ with a central wavelength of $800 \mathrm{~nm}$. The laser beam is focused with an achromatic lens onto an aluminum sample mounted on a computer-controlled XYZ translation stage. A half-wave plate and polarizing beam-splitter cube are used for varying the laser power. The $1 \mathrm{D}$ array of parallel microgrooves is produced by raster scanning of the sample across the laser beam. To find efficient wicking surface structures, we vary laser fluence $F$, step between scanning lines, scanning speed, focal spot diameter, and pulse repetition rate. In the result of these tests, we find that the most efficient wicking performance 
is observed for microgrooves containing LIPSS-textured areas and microholes on both valleys and ridges of the microgrooves. In our study, this structure is produced using laser fluence of $8.6 \mathrm{~J} / \mathrm{cm}^{2}$, step between scanning lines of $100 \mu \mathrm{m}$, pulse repetition rate of $1000 \mathrm{~Hz}$, and scanning speed of $1 \mathrm{~mm} / \mathrm{s}$. Aluminum plates purchased from Goodfellow are processed in the ambient air at temperature of $23{ }^{\circ} \mathrm{C}$ and relative humidity of $50 \%$ measured using a humidity sensor HMP7 from Vaisala (Helsinki, Finland). The dimensions of the laser-textured surface area are $20 \times 50 \mathrm{~mm}$. After laser processing, the samples were cleaned with alcohol and deionized water in an ultrasonic bath for $3 \mathrm{~min}$ in each liquid for removing redeposited debris and dried by blowing compressed nitrogen. The structural features of the produced wicking structure are studied using a 3D laser scanning microscope VK-X1100 from Keyence and scanning electron microscope (SEM) Sigma 300 from Zeiss (Jena, Germany). Elemental composition of both treated and untreated sample surfaces is examined by an energy dispersive X-ray spectroscopy (EDS) using a Brucker XFlash 6/30 detector (Karlsruhe, Germany). In our study, we prepare three Al samples (\#1, $\# 2$, and \#3) using the same laser processing parameters. Sample \#1 is studied as after laser processing. Samples \#2 and \#3 are further treated in hot water at 82 and $100{ }^{\circ} \mathrm{C}$ for $15 \mathrm{~min}$, respectively, to form an $\mathrm{AlO}(\mathrm{OH})$ surface layer. These hot water treatments are similar to those used in [80].

The wicking functionality of the produced samples is studied by video imaging capillary spreading of deionized water on a horizontally positioned sample. The video imaging setup is shown in Figure 1. An aluminum sample is mounted on a heater. The temperature of the sample surface is regulated by a temperature controller (TCN4S from Autonics, Busan, South Korea) and thermocouple (5TC-TT-K-30-36 from Omega, Norwalk, CT, USA) attached onto untreated sample surface. Water is supplied to the wicking surface structure from a pendant $10-\mu \mathrm{L}$ drop formed by a syringe pump Elite 11 from Harvard Apparatus Inc. (Holliston, MA, USA). The capillary flow of water is captured by a high-speed VEO 710L Phantom camera at a rate of 1000 frames per second (fps). The wicking dynamics are studied at sample temperatures $T=23,40,60,80,100$, and $120^{\circ} \mathrm{C}$ under ambient air conditions with relative humidity of $50 \%$ and temperature of $23^{\circ} \mathrm{C}$. Using video recordings of water flow, we find both water spreading distance $h$ and water spreading velocity as a function of time $t$, which we obtain as a numerical derivative $\Delta h / \Delta t$, where $\Delta h$ is the difference of spreading distance between two consecutive video frames and $\Delta t=10^{-3} \mathrm{~s}$.

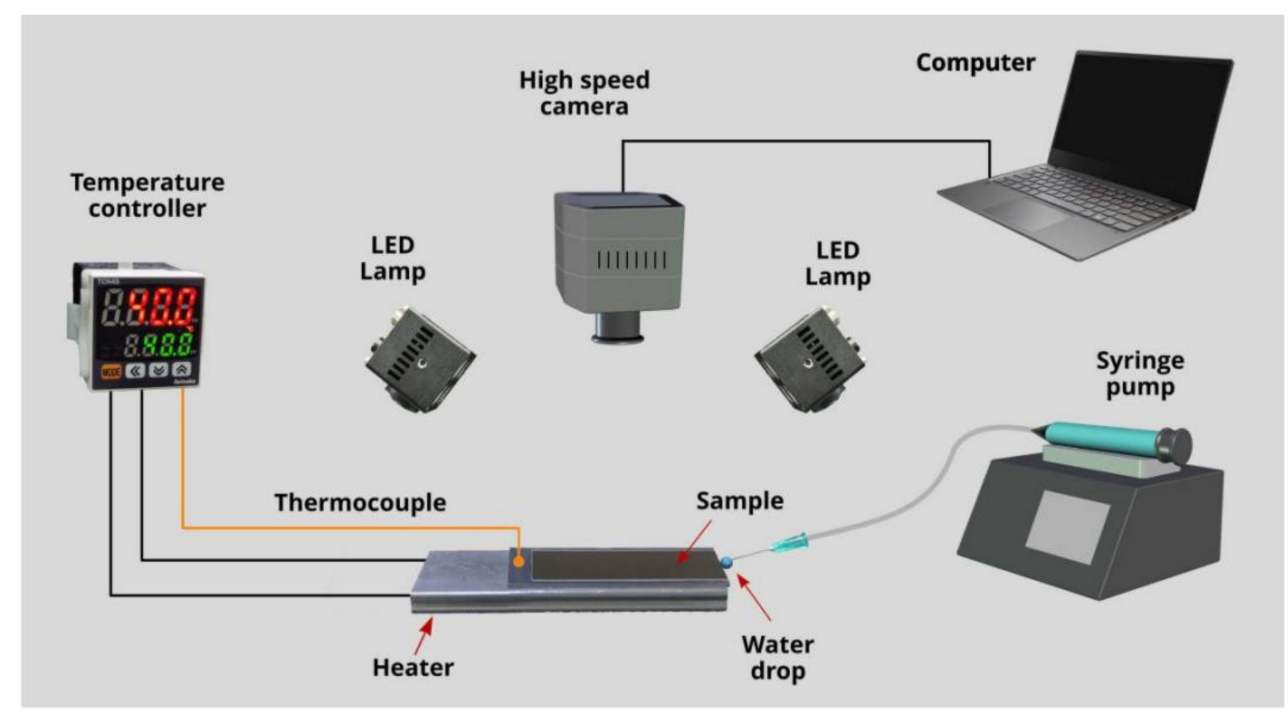

Figure 1. Experimental setup for high-speed video imaging of water spreading on a wicking surface at various temperatures. 


\section{Results and Discussion}

The period and averaged depth of the basic capillary microgrooves are measured to be $100 \pm 12 \mu \mathrm{m}$ and $88 \pm 7 \mu \mathrm{m}$, respectively. The surface textures produced on a microgroove bottom and ridge are shown in Figure 2. As seen, in addition to common random nano/microstructures, the microgroove texture includes a large number of LIPSS areas and fine microholes with a LIPSS-textured surface. The microhole formation results from a "keyhole" effect observed after ablation with continuous wave (CW), long-pulse, and ultrashort-pulse lasers [86-90]. This effect is caused by the formation of microspots with enhanced laser beam absorption at some surface structures on the crater bottom that results in a higher ablation rate and the creation of a microhole that acts as a focusing cavity and further enhances the laser beam absorption due to multiple reflections [86-89]. It has been previously found that the formation of random deep microholes at the crater bottom following static multipulse femtosecond laser ablation is observed at laser fluences above $\sim 3 \mathrm{~J} / \mathrm{cm}^{2}$ [88]. Under our dynamic scanning ablation conditions, the fine microholes form at $F>5.1 \mathrm{~J} / \mathrm{cm}^{2}$. Both increasing the laser fluence and decreasing the scanning speed result in a larger number of produced microholes. The diameter and depth of the microholes in our capillary structure are mostly in a range of 5-30 $\mu \mathrm{m}$ and 5-40 $\mu \mathrm{m}$, respectively. As seen in Figure 2, the LIPSS areas are randomly formed on the ridge, bottom, and walls of a microgroove. Due to the geometrical complexity of the microgroove structure, the LIPSS morphology significantly varies. An important factor in variation of the LIPSS morphology is the laser beam incidence angle that determines the LIPSS period. The LIPSS period $d$ on a metal irradiated with a linearly polarized laser light in an ambient dielectric medium is given by Equation (1) [1,19,91,92]:

$$
d=\lambda_{\text {las }} /\left(\operatorname{Re}[\eta] \mp \sin \theta_{i}\right), \text { with } \mathbf{g} \| \mathbf{E}
$$

where $\lambda_{\text {las }}$ is the wavelength of incident laser light, $\theta_{i}$ is the angle of laser beam incidence, $\eta=\left[\varepsilon_{d} \varepsilon_{\text {metal }} /\left(\varepsilon_{d}+\varepsilon_{\text {metal }}\right)\right]^{1 / 2}$ is the effective refractive index of the dielectric-metal interface for surface plasmons, $\varepsilon_{d}$ is the dielectric constant of the ambient dielectric medium, $\varepsilon_{\text {metal }}$ is the dielectric constant of the metal, $\operatorname{Re}[\eta]$ is the real part of $\eta, \mathbf{g}$ is the grating vector of LIPSS, and $\mathbf{E}$ is the tangential component of electrical field vector of the incident laser beam. Typically, the period of LIPSS generated by the femtosecond pulses at $\theta_{i} \approx 0$ is in a range between 100 and $600 \mathrm{~nm}$. Depending on the laser ablation conditions, larger LIPSS periods can be also produced at a normal incidence angle [93]. At $\theta_{i}>0$, the LIPSS period increases, being in a range of $1-4 \mu \mathrm{m}$ at $30^{\circ}<\theta_{i}<80^{\circ}$ [91]. Another important factor in the variation of the LIPSS period is the effective refractive index of the dielectric-metal interface $\eta$ for surface plasmons that depends on morphology of fine nanostructures formed during multipulse ablation [30]. The major laser parameters that govern the morphology of fine microstructures are laser fluence and number of overlapping laser pulses [1]. In our study, the number of overlapping laser pulses is 120 . Figure 2 shows that the microgroove surface is textured with random both nano- and fine microstructures of various shapes typically formed by multipulse femtosecond laser ablation [1]. The dimensions of these random structures are in a range between $35 \mathrm{~nm}$ and $5 \mu \mathrm{m}$.

Previously, it has been shown that femtosecond laser ablation in air causes aluminum surface to oxidize [94]. The elemental compositions of an aluminum surface before and after laser processing are demonstrated in Figure $3 a, b$, respectively. One can see that oxygen content after laser processing increases by about seven times. The treatments of the laser-processed samples in hot water results in further increasing the oxygen content (see Figure $3 \mathrm{c}, \mathrm{d}$ ). Since the capillary flow of water on laser-treated aluminum without Boehmite treatment (sample \#1) is studied at surface temperatures ranging from 23 to $120{ }^{\circ} \mathrm{C}$, the elemental composition of the surface can be modified by chemical interaction of hot aluminum surface with water during experiments in a way similar to Boehmite treatment. To assess this modification, we performed an EDS analysis of the sample \#1 after our experiments on the water spreading dynamics. The results of this EDS analysis, 
shown in Figure 3e, reveal the increase in oxygen content. This oxygen increase is slightly smaller than that on samples \#2 and \#3 after hot water treatments as can be seen from a comparison of Figure 3c-e. The laser-treated samples appear pitch black after laser processing, demonstrating black-metal optical properties with broadband light absorption [1] However, all the studied samples exhibit some loss of their blackness after contact with hot water, indicating a degradation of light absorption properties caused by $\mathrm{AlO}(\mathrm{OH})$ surface layer formation.

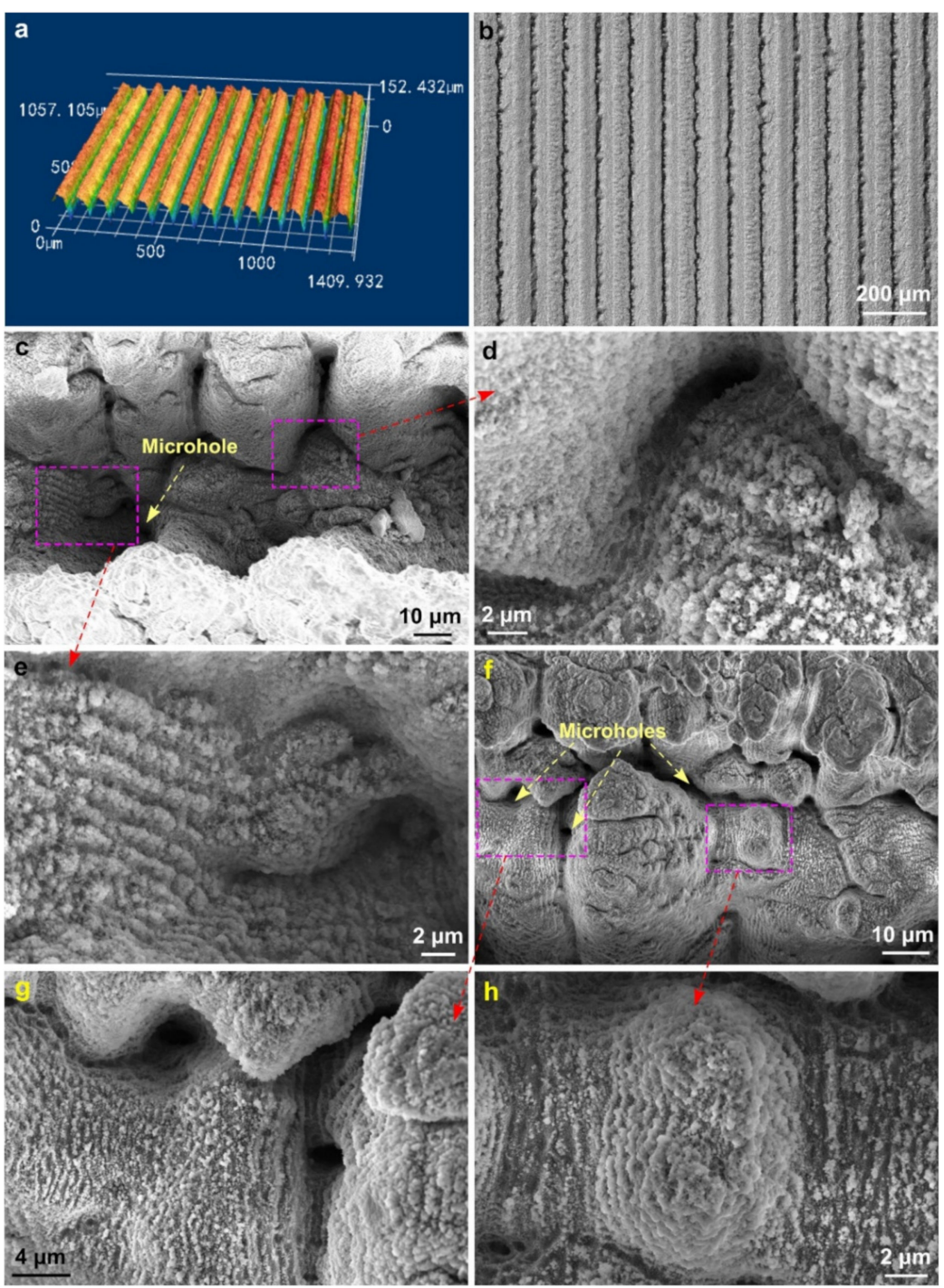

Figure 2. (a) Three-dimensional optical image of the array of parallel microgrooves. (b) Optical microscope image of the array of parallel microgrooves. (c) SEM image of a microgroove valley with areas textured by laser-induced periodic surface structures (LIPSS). (d) Magnified SEM image of LIPSS-textured area near microgroove wall. (e) Magnified SEM image of LIPSS-textured area in a microhole. (f) SEM image of a microgroove ridge with LIPSS-textured areas. (g) Magnified SEM image of LIPSS-textured area in ridge microholes. (h) Magnified SEM image of LIPSS-textured area around a ridge microcolumn. 
a

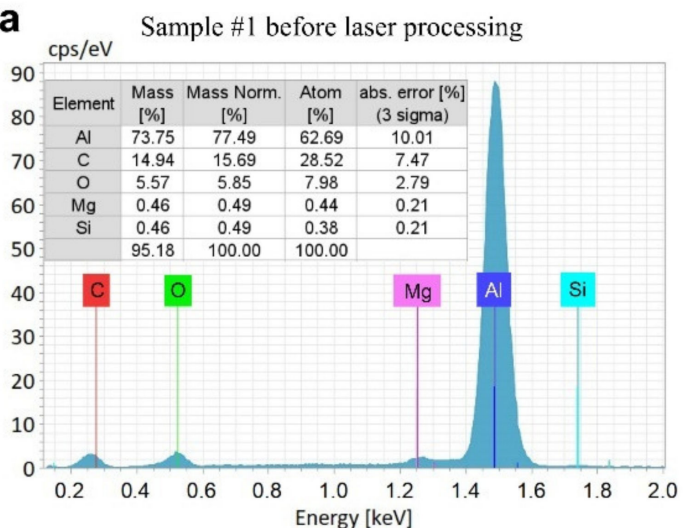

C

Laser-treated sample \#2 after Boehmite treatment at $82{ }^{\circ} \mathrm{C}$ for $15 \mathrm{~min}$

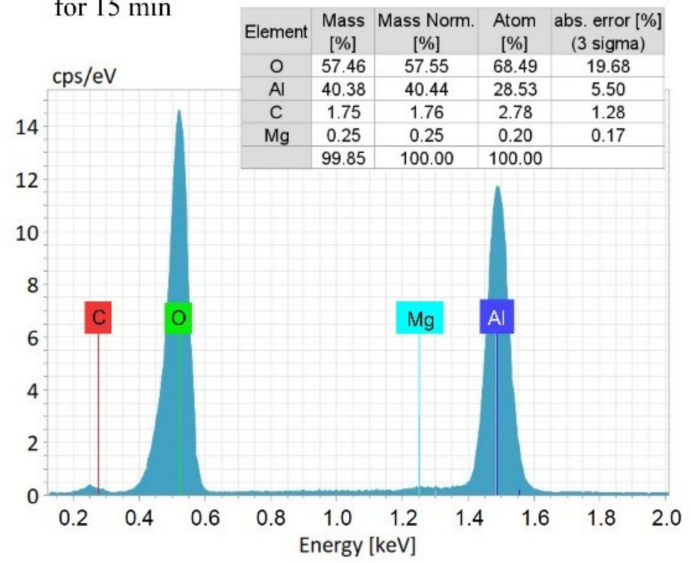

b

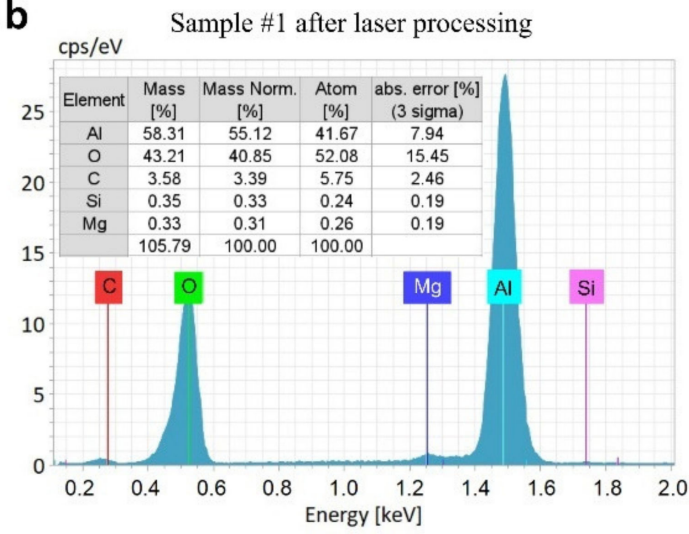

d

Laser-treated sample \#3 after Boehmite treatment at $82{ }^{\circ} \mathrm{C}$ for $15 \mathrm{~min}$

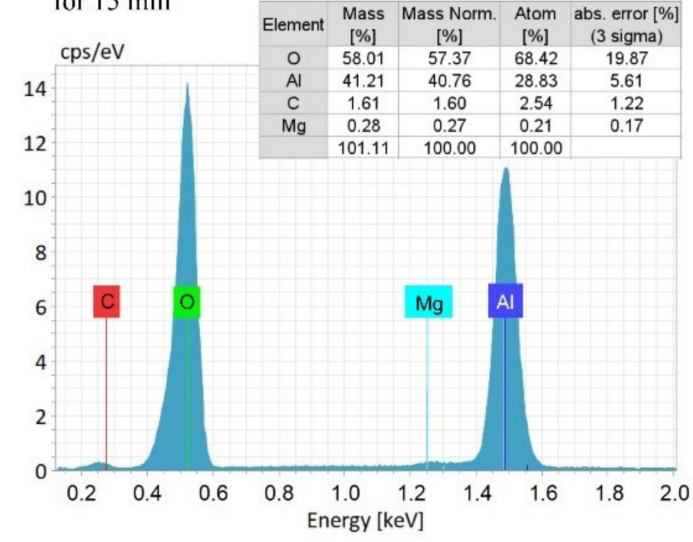

e Laser-treated sample \#1 after experiments on capillary properties at $23-120^{\circ} \mathrm{C}$

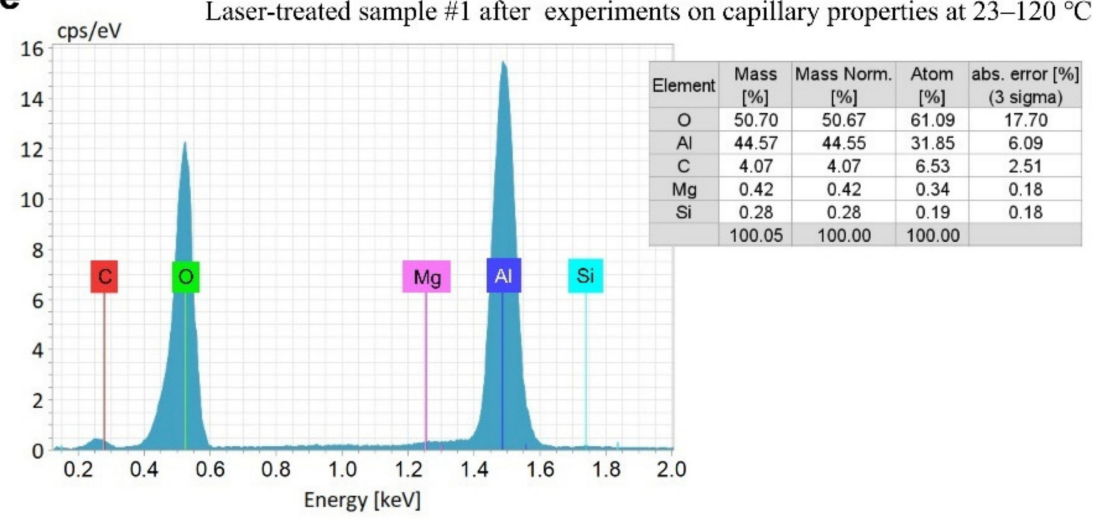

Figure 3. (a) Elemental composition of the sample \#1 surface before laser processing. (b) Elemental composition of a sample surface after laser processing (sample \#1). (c) Elemental composition of the sample surface after water treatment at $82{ }^{\circ} \mathrm{C}$ for $15 \mathrm{~min}$ (sample \#2). (d) Elemental composition of the sample surface after water treatment at $100{ }^{\circ} \mathrm{C}$ for $15 \mathrm{~min}$ (sample \#3). (e) Elemental composition of the sample \#1 after water capillary flow experiments at $23-120^{\circ} \mathrm{C}$.

The data on the capillary flow dynamics on the surface of sample \#1 at room temperature $\left(T=23^{\circ} \mathrm{C}\right)$ are presented in Figure 4. The plot of the water spreading distance $h$ as a function of time $t$ is shown in Figure $4 \mathrm{a}$. It is seen that water spreads for a distance of $50 \mathrm{~mm}$ in about $3000 \mathrm{~ms}$, demonstrating a very fast capillary flow. Figure $4 \mathrm{~b}$ shows $h(t)$ dependence in the initial time domain $0<t<100 \mathrm{~ms}$, where acceleration and inertial stages of the capillary flow typically take place [64,85,95-99]. It is seen that the spreading distance achieves an extremely large value of $17.3 \mathrm{~mm}$ at $100 \mathrm{~ms}$. The plot of the capillary flow velocity $v$ as function of time in Figure $4 \mathrm{c}$ demonstrates an extraordinarily high spreading velocity that reaches a maximum value of $452 \mathrm{~mm} / \mathrm{s}$ in the initial capillary flow stage. 
This value of the maximum spreading velocity exceeds those that have been previously observed in 1D microgroove structures (370 mm/s in [85] and $120 \mathrm{~mm} / \mathrm{s}$ in [100]). Using the same approach for identifying the inertial regime as in $[64,85]$, we find in our study that the inertial regime, where the spreading distance is a quasilinear function of time, lasts until about 70 ms. Snapshots a1, b1, b2, b3, b4, c1, c2, and c3 illustrate the water spreading in the time domain $0<t<90 \mathrm{~ms}$. The physical processes of the studied here capillary flow are similar to those in the 1D array of microgrooves on silicon reported in [85], where a detailed discussion of the mechanisms governing water flow is given. Figure $4 \mathrm{~d}$ shows the overall $v(t)$ plot in the time domain $0<t<3200 \mathrm{~ms}$. It is seen that the velocity quickly decreases after the inertial flow stage down to about $15-20 \mathrm{~mm} / \mathrm{s}$ at $t=400 \mathrm{~ms}$ (see insets i1 and i2). This quick decrease of the velocity occurs in the visco-inertial capillary flow regime that takes place between the inertial $(h \propto t)$ and Washburn $\left(h \propto t^{1 / 2}\right)$ regimes [101,102]. The liquid flow dynamics in the visco-inertial regime follows the relationship $h \propto t^{\mathrm{n}}$, where $n$ gradually reduces from 1 to 0.5 [102]. Snapshots $\mathrm{c} 3$ and $\mathrm{d} 1$ illustrate the water flow in the visco-inertial stage. To identify the time domain of Washburn's $t^{1 / 2}$ regime, we plotted $h$ as a function of $t^{1 / 2}$ in Figure 4e, where one can see that the Washburn capillary flow takes place between 400 and $2000 \mathrm{~ms}$. Snapshots e1, e2, and e3 show the water flow in the Washburn regime. As seen in Figure $4 \mathrm{~d}$ and its insets i1 and i2, the decrease in the spreading velocity is slow during both Washburn's stage and the final flow stages as compared with that in the visco-inertial regime. The water spreading in the final capillary flow stages is demonstrated by Snapshots e4 and e5.

Figure 5 presents the data on the capillary flow dynamics of sample $\# 1$ at $60{ }^{\circ} \mathrm{C}$. The plot of the spreading distance as a function of time in Figure 5a shows that the water spreading distance of $50 \mathrm{~mm}$ is achieved in $2040 \mathrm{~ms}$, demonstrating a faster capillary flow than that at $23{ }^{\circ} \mathrm{C}$. The inset in Figure 5 a demonstrates a comparison of the $h(t)$ dependences at 23 and $60^{\circ} \mathrm{C}$. It is seen that at $0<t<400 \mathrm{~ms}$ the spreading distance is about the same, indicating a negligible temperature effect on water flow. However, the temperature effect on the water spreading clearly manifests itself at $t>400 \mathrm{~ms}$. The capillary action enhancement with increasing temperature has been previously explained in [85]. The detailed $h(t)$ dependence at $0<t<100 \mathrm{~ms}$ in Figure $5 \mathrm{~b}$ shows a very large spreading distance in the initial stage, reaching about $17.9 \mathrm{~mm}$ at $t=100 \mathrm{~ms}$. The inertial flow regime, where $h$ is a quasilinear function of time [64,85], occurs between $3 \mathrm{~ms}$ and about $70 \mathrm{~ms}$, as indicated in Figure $5 \mathrm{~b}$. The $v(t)$ plot in Figure $5 \mathrm{c}$ reveals an acceleration stage between 0 and $3 \mathrm{~ms}$, where the capillary flow velocity increases from 0 to an extremely high value of about $513 \mathrm{~mm} / \mathrm{s}$. Water spreading in the end of this acceleration stage is illustrated by Snapshot $\mathrm{b} 1$. The initial water spreading dynamics in the time domain $0<t<90 \mathrm{~ms}$ are demonstrated by Snapshots a1, b1, c1, c2, b2, b3, b4, and c3. Water spreading in the inertial regime is illustrated by Snapshots b1, c2, b2, b3, and b4. The plot $h\left(t^{1 / 2}\right)$ in Figure $5 \mathrm{~d}$ shows that the Washburn regime occurs between 400 and $1100 \mathrm{~ms}$, as indicated in Figure 5a. Thus, the visco-inertial regime, where $h \propto t^{\mathrm{n}}$ with $1>n>0.5$, takes place between 70 and $400 \mathrm{~ms}$. Figure $5 \mathrm{e}$ presents the overall $v(t)$ dependence in the entire studied time domain $(0<t<2040 \mathrm{~ms})$. It is seen that the velocity significantly reduces in the viscoinertial regime down to about $25 \mathrm{~mm} / \mathrm{s}$ (see Figure 5e and its inset i1). Snapshots c3, d1, $\mathrm{d} 2$, and $\mathrm{d} 3 \mathrm{demonstrate}$ water spreading in the visco-inertial regime. In the Washburn stage $(400<t<1100 \mathrm{~ms})$, the velocity decreases to about $12 \mathrm{~mm} / \mathrm{s}$, as seen in Figure $5 \mathrm{e}$ and its inset i2. Snapshots d2, e1, and d4 illustrate the water spreading in the Washburn stage. Water spreading after Washburn's stage is demonstrated in Snapshots e2 and e3. In summary, the data obtained in the temperature range between 23 and $60{ }^{\circ} \mathrm{C}$ show the excellent wicking properties of the created aluminum material, indicating its practical applicability in M-cycle air-conditioners for enhancing their efficiency $[76,79,103,104]$. 

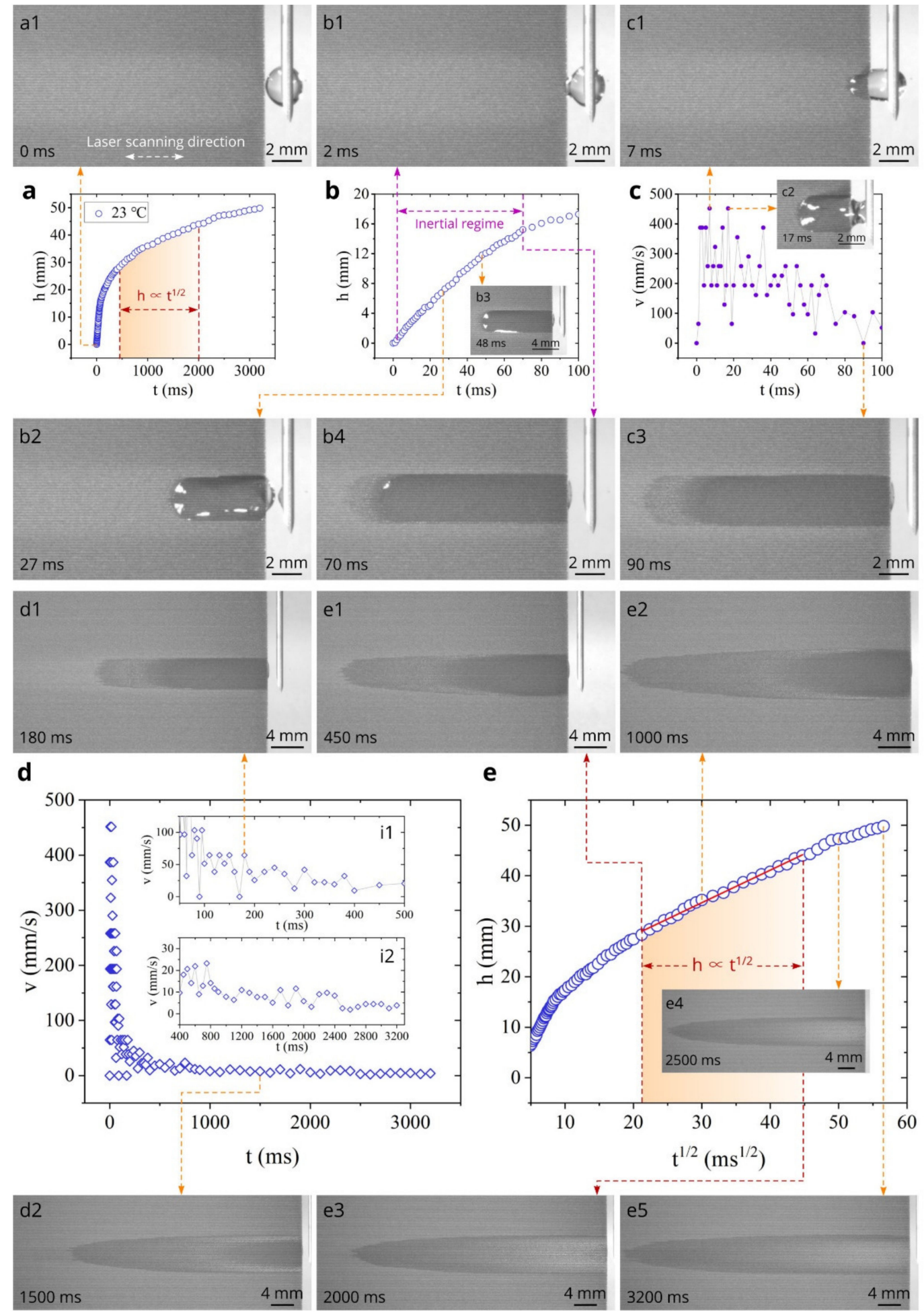

Figure 4. Experimental $h(t)$ and $v(t)$ plots along with snapshots of water spreading at $23^{\circ} \mathrm{C}$ for sample \#1. (a) Overall plot of the spreading distance as a function of time between 0 and $3200 \mathrm{~ms}$ (a1 is a snapshot of the sample surface and water drop at $t=0$ ). (b) Detailed plot of the spreading distance as a function of time between 0 and 100 ms (b1-b4 are snapshots of water spreading associated with $h(t)$ dependence). (c) Plot of the velocity as a function of time between 0 and $100 \mathrm{~ms}$ (c1-c3 are snapshots of water spreading associated with $v(t)$ dependence). (d) Overall plot of the velocity as a function of time between 0 and $3200 \mathrm{~ms}(\mathrm{~d} 1, \mathrm{~d} 2$ are snapshots of water spreading associated with $v(t)$ dependence. The insets i1 and i2 show detailed $v(t)$ dependencies in the time domains of 100-500 and 400-3200 ms, respectively). (e) Plot of the spreading distance as a function of $t^{1 / 2}$ (e1-e5 are snapshots of water spreading associated with Washburn's regime). (Note: Bleaching of surface in the middle of the sample seen in Snapshots of both this and Figures 5 and 6 is discussed in paper later). 


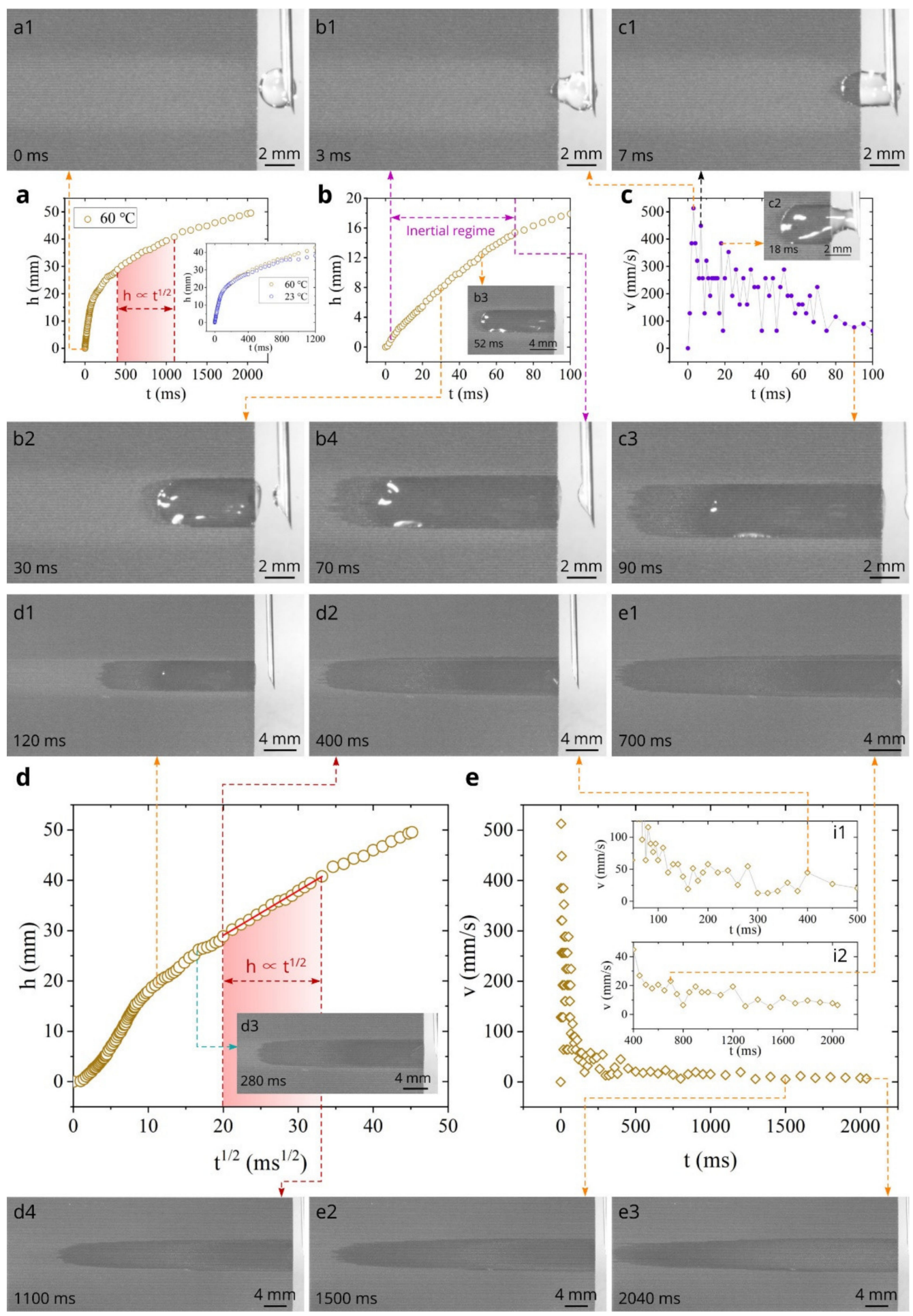

Figure 5. Obtained $h(t)$ and $v(t)$ plots along with snapshots of water spreading at $60{ }^{\circ} \mathrm{C}$ for sample \#1. (a) Overall plot of the spreading distance as a function of time between 0 and $2040 \mathrm{~ms} \mathrm{(a1} \mathrm{is} \mathrm{a} \mathrm{snapshot} \mathrm{of} \mathrm{the} \mathrm{sample} \mathrm{surface} \mathrm{and} \mathrm{water} \mathrm{drop} \mathrm{at}$ $t=0)$. (b) Detailed plot of the spreading distance as a function of time between 0 and $100 \mathrm{~ms}$ (b1-b4 are snapshots of water spreading associated with $h(t)$ dependence). (c) Plot of the velocity as a function of time between 0 and $100 \mathrm{~ms}$ (c1-c3 are snapshots of water spreading associated with $v(t)$ dependence). (d) Plot of the spreading distance as a function of $t^{1 / 2}(\mathrm{~d} 1$, $\mathrm{d} 3$ are snapshots of water spreading related to visco-inertial regime; $\mathrm{d} 2$, $\mathrm{d} 4$ are snapshots of water spreading related to Washburn's regime). (e) Overall plot of the velocity as a function of time between 0 and 2040 ms (e1-e3 are snapshots of water spreading associated with $v(t)$ dependence. The insets i1 and i2 show detailed $v(t)$ dependencies in the time domains of 100-500 and 400-2040 ms, respectively). 

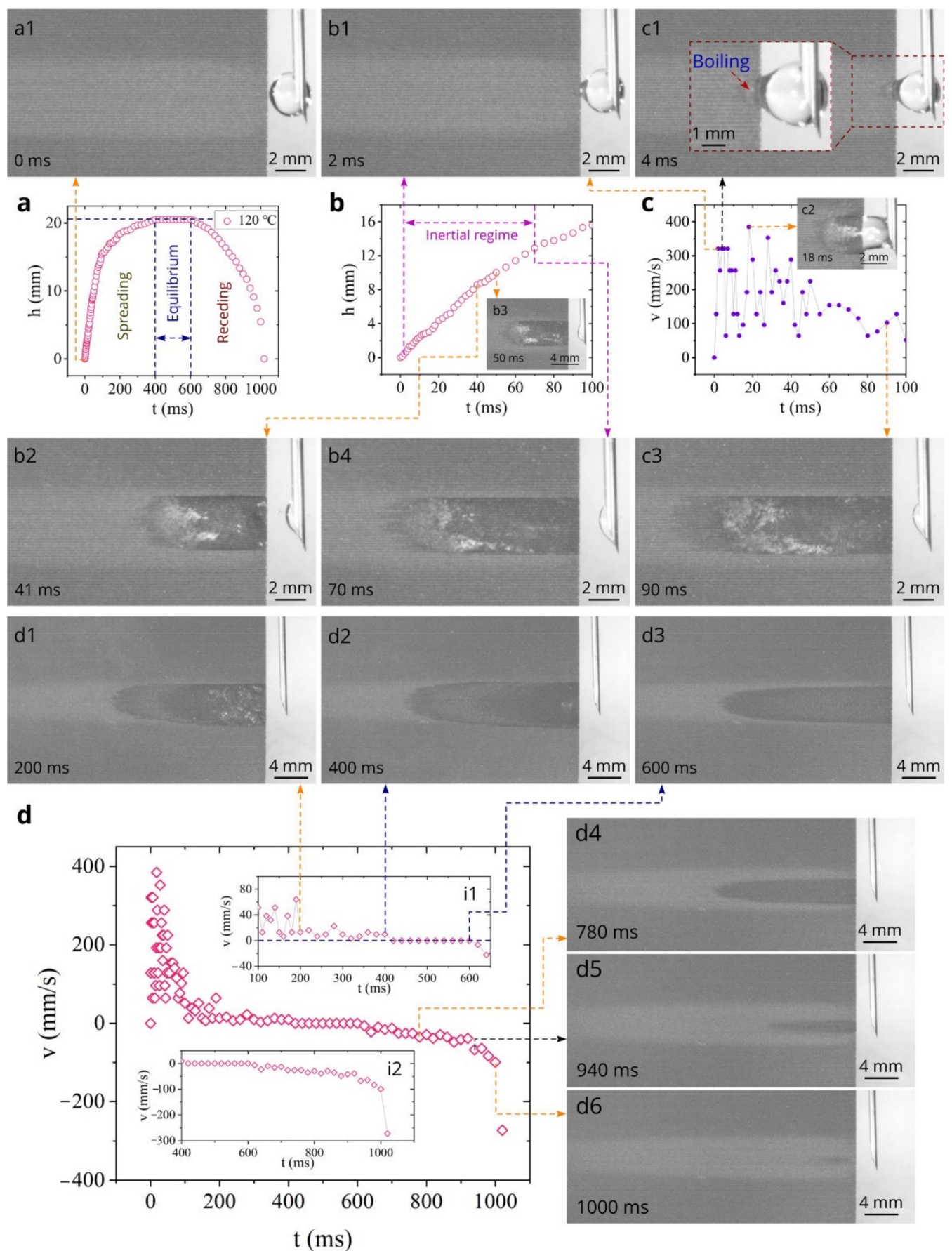

Figure 6. The $h(t)$ and $v(t)$ dependencies at $120^{\circ} \mathrm{C}$ and snapshots of water behaviors in spreading, equilibrium, and receding regimes for sample \#1. (a) The overall plot of the spreading distance as a function of time (a1 is a snapshot of the sample surface and water drop at $t=0)$. (b) Detailed $h(t)$ plot in the time domain between 0 and $100 \mathrm{~ms}$ (b1-b4 are snapshots of water spreading associated with $h(t)$ dependence). (c) Detailed plot of the spreading velocity as a function of time between 0 and $100 \mathrm{~ms}$ ( $\mathrm{c} 1-\mathrm{c} 3$ are snapshots of water spreading associated with $v(t)$ dependence). (d) The overall plot of spreading and receding velocities as a function of time $(\mathrm{d} 1-\mathrm{d} 6$ are snapshots of water spreading associated with overall $v(t)$ dependence. The insets i1 and i2 show detailed $v(t)$ dependencies in the time domains of 100-650 and 400-1020 ms, respectively).

The wicking dynamics of laser-fabricated materials have been previously studied at temperatures below the boiling point of water. Here, we extend the studied temperature range up to $120{ }^{\circ} \mathrm{C}$. Figure 6 presents our results on the water spreading, boiling, and receding (drying) dynamics obtained at $120{ }^{\circ} \mathrm{C}$. The overall $h(t)$ dependence is demonstrated in Figure 6a, where it is seen that initially the water front spreads on the hot surface, 
reaches a maximum spreading distance of $20.5 \mathrm{~mm}$ at $t=400 \mathrm{~ms}$, remains immovable at $400<t<600 \mathrm{~ms}$, and then recedes due to evaporation until the complete evaporation of water at $t=900 \mathrm{~ms}$. These water front behavior stages are indicated in Figure $6 \mathrm{a}$ as "spreading", "equilibrium", and "receding". Snapshots d2 and d3 show that although the spreading distance remains about the same in the equilibrium stage, the wetted surface area becomes narrower with time. The detailed $h(t)$ and $v(t)$ plots in the time domain $0<t<100 \mathrm{~ms}$ shown in Figure 6b,c demonstrate that the water spreading distance achieves about $15.6 \mathrm{~mm}$ at $100 \mathrm{~ms}$ and the maximum spreading velocity attains about $320-325 \mathrm{~mm} / \mathrm{s}$ between 2 and $4 \mathrm{~ms}$, exhibiting an extremely strong capillary action even at the temperature above the boiling point of water. Snapshots a1, b1, b2, b3, c1, c2, and c3 illustrate the water behaviors in the time domain $0<t<100 \mathrm{~ms}$. Snapshot b1 shows the water spreading in the end of the acceleration stage $(t=2 \mathrm{~ms})$ when the spreading velocity achieves about $325 \mathrm{~mm} / \mathrm{s}$. The higher velocities of about $385 \mathrm{~mm} / \mathrm{s}$ and $353 \mathrm{~mm} / \mathrm{s}$ are observed at $t=18$ and $28 \mathrm{~ms}$, respectively. These velocity enhancements are correlated with big bubble bursts that can push water forward. As seen in Snapshots c1, boiling begins at $t=4 \mathrm{~ms}$ and completes at about $400 \mathrm{~ms}$ (see Snapshot d2) when the equilibrium stage is almost finished. The evolution of boiling in the spreading water film is illustrated by Snapshots c1, c2, b2, b3, b4, $\mathrm{c} 3, \mathrm{~d} 1$, and $\mathrm{d} 2$. It is seen that, initially, the boiling area closely follows the water spreading front (see Snapshots c1, b2, c2, and b4). At a later time, the boiling area spreading stops and it begins receding towards to the right edge of the sample. As seen in Snapshot d2, boiling terminates near the right edge of the sample at about $400 \mathrm{~ms}$ when the spreading stage comes to the end. This evolution of the boiling area is explained by the decrease in the water film thickness to a level of 1-10 $\mu \mathrm{m}$ that does not support nucleate boiling [105]. After the boiling termination, the water film thickness becomes small in the entire wetted area, thus causing evaporation to occur through a thin film evaporation mechanism [106] that governs the water behavior in the equilibrium and receding stages. The overall plot of the spreading and receding velocities as functions of time is shown in Figure $6 \mathrm{~d}$. The inset i1 shows in detail the $v(t)$ dependence in the end of spreading stage and in the equilibrium stage, where $v \approx 0 \mathrm{~mm} / \mathrm{s}$. The dynamics of the evaporating water film in the receding regime is illustrated by Snapshots $\mathrm{d} 3$ to $\mathrm{d} 6$. It is seen that after the equilibrium stage, the water film front begins to recede with an increasing velocity, achieving an extremely high value of about $272 \mathrm{~mm} / \mathrm{s}$ in the end of the receding stage (see the inset i2). As seen in Snapshot d6, the sample surface becomes completely dry at about $1020 \mathrm{~ms}$. Washburn's dynamics of water spreading was not found at $120^{\circ} \mathrm{C}$. In summary, our study on wicking dynamics at $120^{\circ} \mathrm{C}$ shows the excellent wicking performance of the developed material even above the boiling point of water.

The classic Washburn $h \propto t^{1 / 2}$ flow dynamics [107] is observed in many capillary systems $[12,95,100,108-113]$. It is often considered as a universal one, being the standard in comparing capillary flows [114]. For smooth V-microgrooves, Washburn's capillary flow is given by $h^{2}=K(\alpha, \theta)[\gamma d / \mu] t$, where $K(\alpha, \theta)$ is the geometry term with $\alpha$ being the groove angle, $\theta$ is the contact angle, $d$ is the groove depth, $\gamma$ is the liquid surface tension, and $\mu$ is the liquid viscosity [109]. In the Washburn regime, the flow of a liquid at room temperature is governed by capillary and viscous forces [107]. At elevated temperatures, it can be affected by evaporation. Previously, it has been found that the $h \propto t^{1 / 2}$ regime lifetime decreases with increasing temperature due to effect of evaporation that deviates the liquid flow from the Washburn dynamics [85]. Figure 7a presents our data on the lifetime of Washburn's regime in the studied temperature range at air pressure of 1 atmosphere. It is seen that the Washburn regime is observed in the temperature range between 23 and $80{ }^{\circ} \mathrm{C}$. Its onset time remains almost unchanged but its termination time significantly shortens as the temperature increases. The Washburn dynamic is not observed above $T \geq 100{ }^{\circ} \mathrm{C}$, indicating a significant role of evaporation/boiling. To understand the evaporation and boiling effects on the liquid flow dynamics, we perform a comparative analysis of the $h(t)$ dependencies obtained at the studied temperatures. A comparison of the $h(t)$ dependencies at different temperatures in the entire studied time domain is presented in Figure $7 \mathrm{~b}$. It 
is seen that all $h(t)$ dependences are about the same in the time domain between 0 and $100 \mathrm{~ms}$, where the inertial and partially visco-inertial flow regimes occur. At a later time, one can clearly see the effect of the spreading distance increase as the temperature rises between 23 and $80^{\circ} \mathrm{C}$. A detailed comparison of the $h(t)$ dependencies for demonstration of the temperature effect on water spreading in the inertial and visco-inertial flow regimes at $0<t<400 \mathrm{~ms}$ is shown in Figure 7c. This water spreading behavior can be explained by using equations of capillary flow in the inertial [101], visco-inertial [101], and Washburn $[107,109]$ regimes, which show that, in general, the spreading of a liquid can be affected by such temperature-dependent parameters as the contact angle, surface tension, viscosity, and density $\rho$ of the liquid. The water contact angle on an aluminum surface is relatively constant for surface temperatures ranging from 25 to $120^{\circ} \mathrm{C}$ [115]. In the context of capillary flow, the temperature dependences of $\gamma, \mu$, and $\rho$ for water have been previously discussed in [85] and are shown to be favorable for enhancing capillary action with increasing temperature. Therefore, the capillary flow enhancement in our work comes from the temperature dependences of $\gamma, \mu$, and $\rho$. The small temperature effect on water spreading in the inertial regime is explained by the fact that a certain amount of time is needed for water heating. This time can be estimated from the equation for thermal diffusion length $L$ given by $L \approx(D t)^{1 / 2}$, where $D$ is the thermal diffusivity of a material. Assuming that the water film thickness in our capillary structure is about the depth of the microgrooves $(88 \mu \mathrm{m})$, we can estimate a characteristic timescale $t_{\mathrm{d}}$ of heating the water in a microgroove by taking $L=88 \mu \mathrm{m}$ and using a table value of $D=0.0014 \mathrm{~cm}^{2} \mathrm{~s}^{-1}$ for water. This estimation gives us $t_{\mathrm{d}} \approx L^{2} / D \approx 55 \mathrm{~ms}$, which is in an agreement with $t \approx 40-60 \mathrm{~ms}$ in Figure $7 \mathrm{c}$ when temperature effect on water spreading begins to play a role. It is seen in Figure $7 \mathrm{c}$ that $h(t)$ dependences are almost unaffected by evaporation in the inertial and visco-inertial regimes at $23 \leq T \leq 100^{\circ} \mathrm{C}$. At $T=120^{\circ} \mathrm{C}$, water spreading in the inertial regime $(t<70 \mathrm{~ms})$ is slightly affected by boiling; however, the boiling effect on water spreading becomes significant at $t>80 \mathrm{~ms}$.

The common adsorption of hydrophobic hydrocarbons from the ambient air onto metal surfaces often results in the quick degradation of their hydrophilic/capillary properties $[21,116,117]$, making the creation of long-term stable wicking materials a challenging task. It is known that the treatment of aluminum in hot water improves its both hydrophilic/wicking properties and long-term stability [80-83]. These effects result from both the modification of the surface chemistry and the formation of "grass-like" surface nanostructures [82]. Our study on wicking dynamics performed during one week after samples fabrication shows that the wicking properties of the samples treated in hot water (samples \#2 and \#3) are about the same as those of the sample \#1. This observation indicates that femtosecond laser processing provides excellent hydrophilic/wicking properties, making their further improvement with Boehmite treatment a difficult task. To assess the long-term wicking stability of our samples, we use video recording to obtain the time dependence of the dynamic contact angle $\theta$ of a water drop immediately after its deposition onto the sample that allows to find the time $t_{\theta \approx 0}$ when $\theta$ decreases to static zero value $\left(\theta \approx 0^{\circ}\right)$ [64]. To perform these measurements, we use an OSA 200 system for measuring the contact angle in video recording mode at a speed of $50 \mathrm{fps}$. The results obtained over a test period of 170 days are presented in Figure $7 \mathrm{~d}$ as the $t_{\theta \approx 0}(t)$ plots. These plots show that the contact angle becomes zero at about the same $t_{\theta \approx 0} \approx 0.25 \mathrm{~s}$ for all three studied samples tested during few days after their fabrication. However, after 170 days, the time $t_{\theta \approx 0}$ becomes 1.0, 2.6, and $0.48 \mathrm{~s}$ for the samples \#1, \#2, and \#3, respectively. These data show that sample \#2 treated in water at $82{ }^{\circ} \mathrm{C}$ exhibits faster wicking degradation with time as compared with sample \#1, while sample \#3 treated in water at $100^{\circ} \mathrm{C}$ demonstrates a slower degradation. Thus, our study shows that the hot water treatment at $100^{\circ} \mathrm{C}$ can improve the long-term wicking stability of aluminum materials produced by femtosecond laser processing. This finding is important for developing practical long-term stable wicking Al materials. 
a

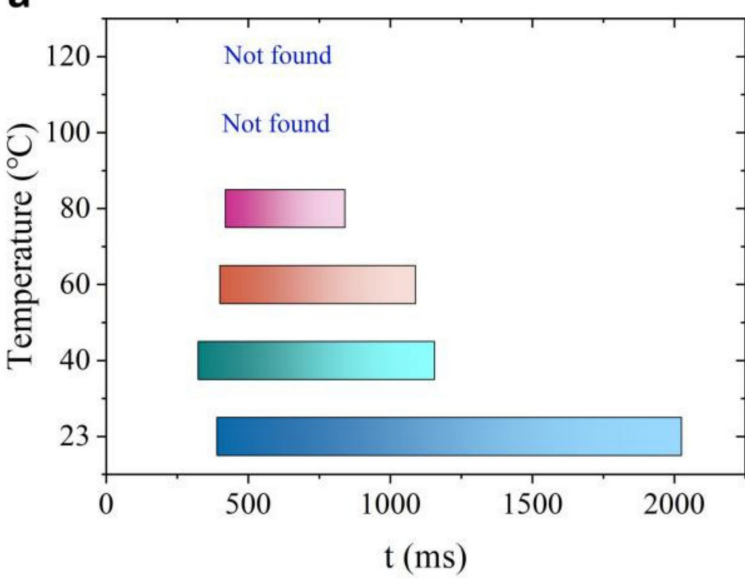

C

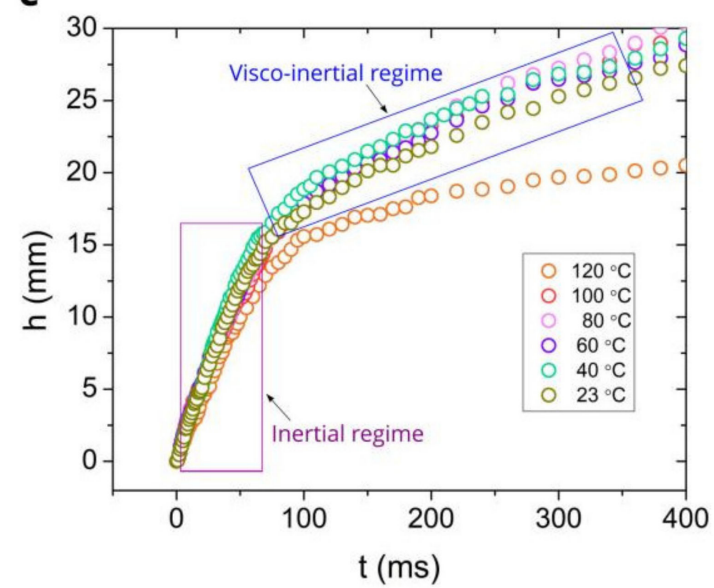

b

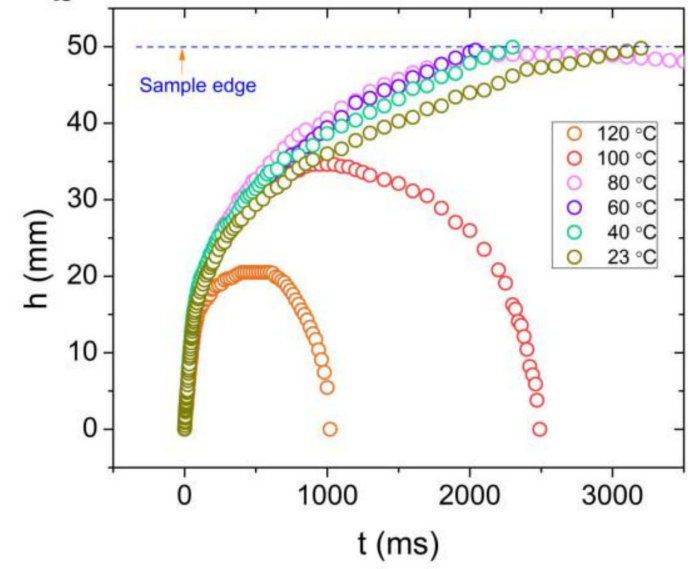

d

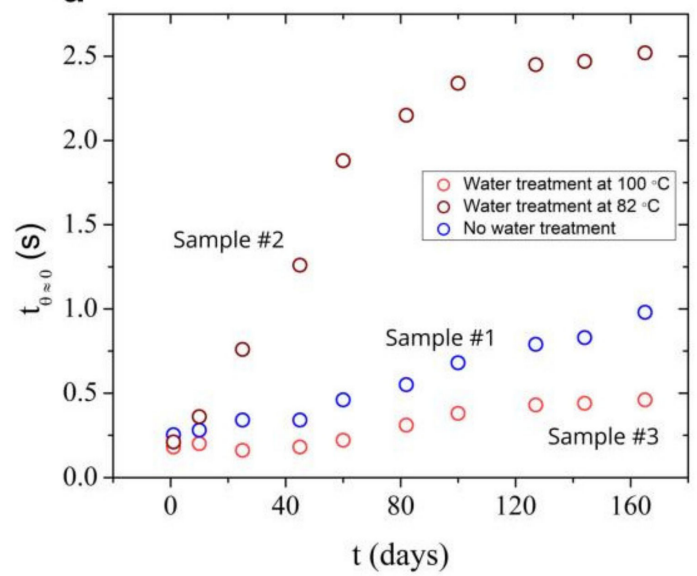

Figure 7. (a) Diagram of Washburn's regime lifetime at different temperatures and air pressure of 1 atmosphere. (b) Comparison of $h(t)$ dependences at different temperatures in the entire studied time domain. (c) Comparison of $h(t)$ dependences at different temperatures in the time domain $0<t<400 \mathrm{~ms}$. (d) The $t_{\theta \approx 0}(t)$ plots of the studied samples.

The femtosecond laser processing that we use also renders the optical properties of a black metal [1] to our samples, in addition to their wicking functionality. Due to high optical absorption, the laser-treated surface appears pitch black (see photo of the sample \#1 in Figure 8a). However, we find that the surface blackness degrades after Boehmite hot water treatments as seen in photos of the samples \#2 and \#3 in Figure 8a. The blackness degradation is also observed in our samples after experiments on water spreading at elevated temperatures (see the photo of sample \#3 in Figure 8b). To assess the morphological changes caused by Boehmite treatment, we took SEM images of sample \#3 after both laser processing and Boehmite treatment shown in Figure $8 c, d$, respectively. It is seen that the Boehmite treatment causes both fine micro- and nanostructural modifications. Highly absorptive optical properties of black metals stem dominantly from the plasmonic absorption of light by surface metal nanostructures [1]. Therefore, the observed blackness degradation can be explained by the depletion of aluminum nanostructures caused by their oxidation during the Boehmite treatment. This also explains the surface bleaching of sample \#1 seen in Snapshots in Figures 4-6 as a consequence of significant oxidation of the sample \#1 surface during our experiments as evidenced by the EDS analysis shown in Figure 3e. To quantitatively characterize the visually observed change of the optical properties, we measure the total (specular + diffuse) reflectance $R$ of our samples in a wavelength range of 250-2500 nm using a Shimadzu spectrophotometer UV-3600 equipped with an integrating sphere. The obtained $R(\lambda)$ dependencies are demonstrated in Figure 8b. For a comparison, the $R(\lambda)$ of a polished sample before laser processing is also shown. These data demonstrate that the interaction of aluminum with hot water reduces the optical absorptance of 
the laser-treated aluminum materials, thus limiting their multifunctional applications in technological areas where both wicking and solar energy harvesting properties are needed.

a

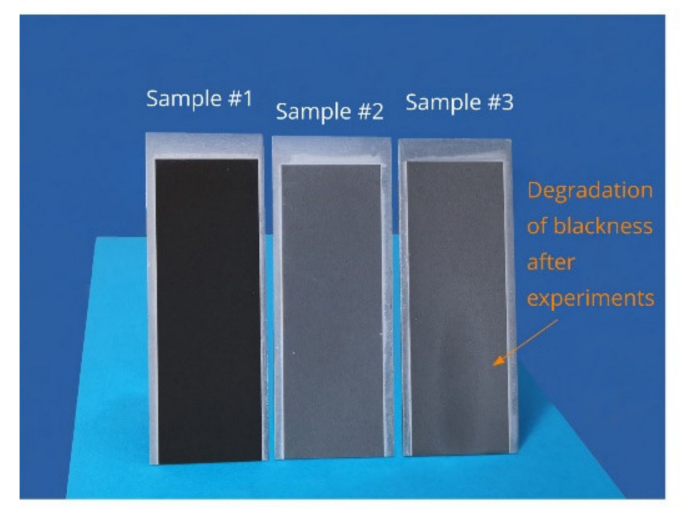

C

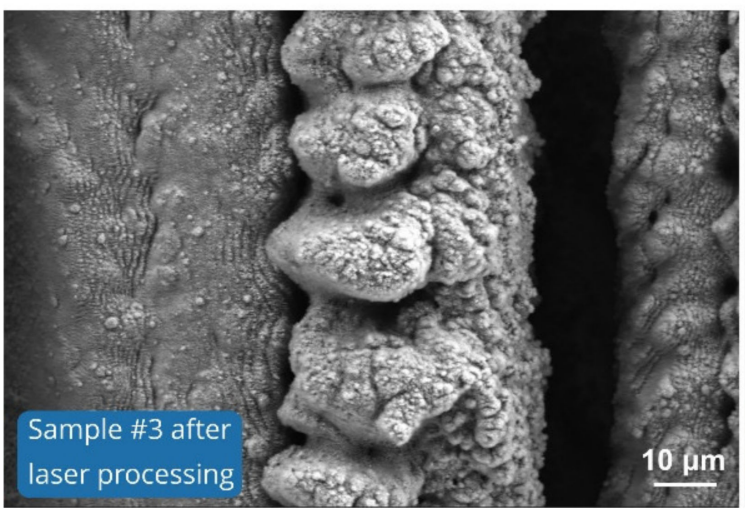

b

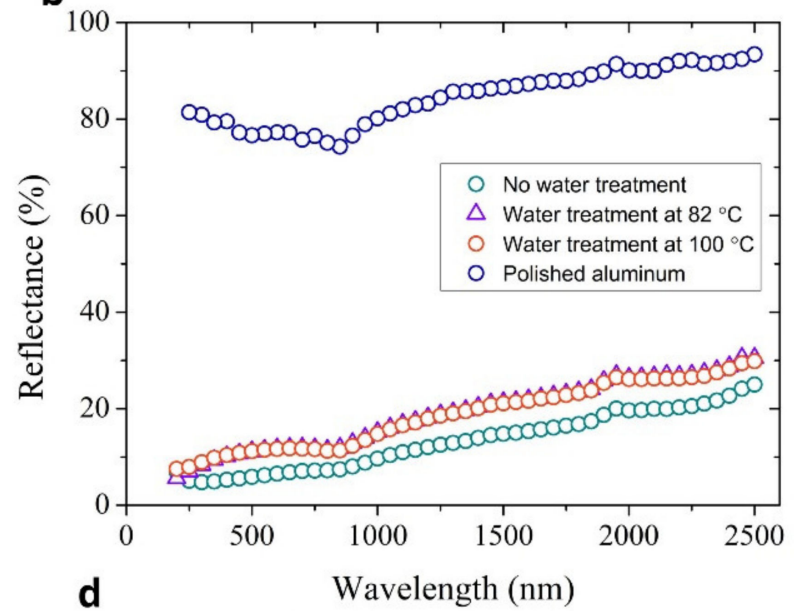

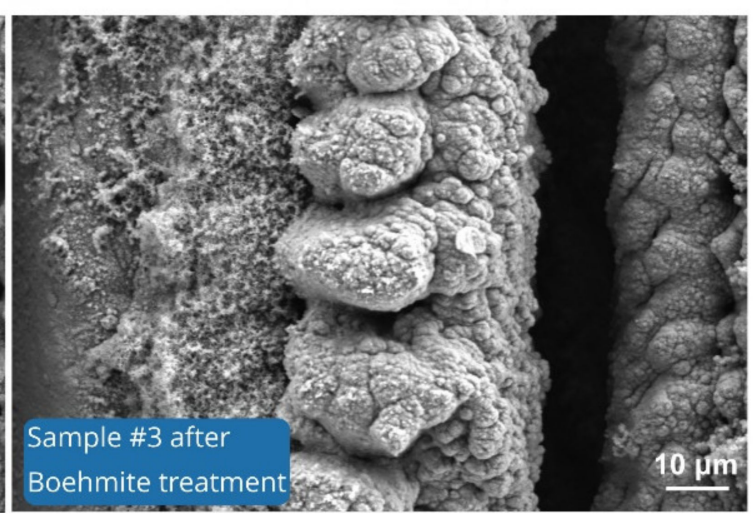

Figure 8. (a) Photos of the samples \#1 (after laser processing), \#2 (after Boehmite treatment at $82{ }^{\circ} \mathrm{C}$ ), and \#3 (Boehmitetreated at $100{ }^{\circ} \mathrm{C}$ and studied for wicking properties). (b) Reflectance of aluminum samples as a function of the light wavelength $\lambda$. For a comparison, the $R(\lambda)$ of a polished sample before laser processing is also shown. (c) SEM image of the surface of the sample \#3 after laser processing. (d) SEM image of the same surface of the sample \#3 after Boehmite treatment.

\section{Conclusions}

In summary, we produced a hierarchical capillary microgroove surface structure that includes both LIPSS and fine microhole textures using the direct femtosecond laser nano/microstructuring of aluminum. The developed material was tested for wicking performance in a wide temperature range of $23-120^{\circ} \mathrm{C}$ at an air pressure of 1 atmosphere. The tests show an extremely high velocity of water spreading that achieves about $450 \mathrm{~mm} / \mathrm{s}$ at $23{ }^{\circ} \mathrm{C}$ and $320 \mathrm{~mm} / \mathrm{s}$ at $120^{\circ} \mathrm{C}$ when the spreading water undergoes intensive boiling. The analysis of the dynamic water behavior demonstrates the decrease of the Washburn regime lifetime with increasing temperature up to $80^{\circ} \mathrm{C}$. The effects of evaporation and boiling on water spreading become significant at $T>80^{\circ} \mathrm{C}$, resulting in vanishing of Washburn's dynamics. At temperatures below the boiling point, evaporation insignificantly affects both the inertial and visco-inertial flow regimes. A pronounced effect of boiling on the visco-inertial regime is found at $120^{\circ} \mathrm{C}$; however, the boiling effect on the inertial regime is small. We find that the hot water treatment at $100{ }^{\circ} \mathrm{C}$ improves the long-term wicking stability of laser-fabricated wicking aluminum materials. The strong capillary action of the created material under water boiling conditions extends the range of its potential applications at high temperatures, such as boilers with enhanced critical heat flux $[82,118,119]$ and M-cycle heat/mass exchangers for enhancing energy efficiency in power generation [76-79,120-122]. 
Author Contributions: Conceptualization, R.F. and A.Y.V.; preparation of samples, R.F., X.Z. and J.Z.; video recording, Z.P., C.Y. and L.D.; data analysis, X.Z., J.Z., Z.P., C.Y. and L.D.; funding acquisition, R.F., R.L., C.L. and W.Y.; writing-original draft preparation, R.F. and A.Y.V.; writing-review and editing, R.F., A.Y.V., R.L., C.L., W.Y. and V.S.M. All authors have read and agreed to the published version of the manuscript.

Funding: This research was funded by Key Project of Science and Technology Research Program of Chongqing Municipal Education Commission of China (KJZD-K202100605), by Chongqing Natural Science Foundation (cstc2021jcyj-msxmX0915), by Chongqing Basic and Frontier Research Project (cstc2018jcyjAX0209), by National Natural Science Foundation of China $(52075063,62105050)$ and by Innovation Research Group of Universities in Chongqing.

Data Availability Statement: Data are contained within the article.

Conflicts of Interest: The authors declare no conflict of interest.

\section{References}

1. Vorobyev, A.Y.; Guo, C. Direct femtosecond laser surface nano/microstructuring and its applications. Laser Photon. Rev. 2013, 7, 385-407. [CrossRef]

2. Zhigilei, L.; Lin, Z.; Ivanov, D.S. Atomistic modeling of short pulse laser ablation of metals: Connections between melting, spallation, and phase explosion. J. Phys. Chem. C 2009, 113, 11892-11906. [CrossRef]

3. Bulgakova, N.M.; Burakov, I.M.; Meshcheryakov, Y.P.; Stoian, R.; Rosenfeld, A.; Hertel, I.V. Theoretical models and qualitative interpretations of Fs laser material processing. J. Laser Micro/Nanoeng. 2007, 2, 76-86. [CrossRef]

4. Shugaev, M.; Wu, C.; Armbruster, O.; Naghilou, A.; Brouwer, N.; Ivanov, D.S.; Derrien, T.J.-Y.; Bulgakova, N.M.; Kautek, W.; Rethfeld, B.; et al. Fundamentals of ultrafast laser-material interaction. MRS Bull. 2016, 41, 960-968. [CrossRef]

5. Vorobyev, A.Y.; Guo, C. Enhanced absorptance of gold following multipulse femtosecond laser ablation. Phys. Rev. B 2005, 72, 195422. [CrossRef]

6. Vorobyev, A.Y.; Guo, C. Femtosecond laser nanostructuring of metals. Opt. Express 2006, 14, 2164-2169. [CrossRef] [PubMed]

7. Wang, X.W.; Kuchmizhak, A.A.; Li, X.; Juodkazis, S.; Vitrik, O.B.; Kulchin, Y.N.; Zhakhovsky, V.V.; Danilov, P.A.; Ionin, A.A.; Kudryashov, S.I.; et al. Laser-induced translative hydrodynamic mass snapshots: Noninvasive characterization and predictive modeling via mapping at nanoscale. Phys. Rev. Appl. 2017, 8, 044016. [CrossRef]

8. Inogamov, N.A.; Zhakhovskii, V.V.; Ashitkov, S.I.; Petrov, Y.V.; Agranat, M.B.; Anisimov, S.I.; Nishihara, K.; Fortov, V.E. Nanospallation induced by an ultrashort laser pulse. J. Exp. Theor. Phys. 2008, 107, 1. [CrossRef]

9. Fang, R.; Vorobyev, A.; Guo, C. Direct visualization of the complete evolution of femtosecond laser-induced surface structural dynamics of metals. Light. Sci. Appl. 2017, 6, e16256. [CrossRef] [PubMed]

10. Povarnitsyn, M.; Fokin, V.B.; Levashov, P.R.; Itina, T. Molecular dynamics simulation of subpicosecond double-pulse laser ablation of metals. Phys. Rev. B 2015, 92, 174104. [CrossRef]

11. Vorobyev, A.Y.; Guo, C. Metal pumps liquid uphill. Appl. Phys. Lett. 2009, 94, 224102. [CrossRef]

12. Vorobyev, A.Y.; Guo, C. Laser turns silicon superwicking. Opt. Express 2010, 18, 6455-6460. [CrossRef] [PubMed]

13. Yin, K.; Duan, J.; Sun, X.; Wang, C.; Luo, Z. Formation of superwetting surface with line-patterned nanostructure on sapphire induced by femtosecond laser. Appl. Phys. A 2015, 119, 69-74. [CrossRef]

14. Starinskiy, S.V.; Rodionov, A.A.; Shukhov, Y.G.; Safonov, A.I.; Maximovskiy, E.A.; Sulyaeva, V.S.; Bulgakov, A.V. Formation of periodic superhydrophilic microstructures by infrared nanosecond laser processing of single-crystal silicon. Appl. Surf. Sci. 2020, 512, 145753. [CrossRef]

15. Zhang, C.; Cheng, L.; Tan, B.; Chen, Z.; Zhang, W.; Liu, Z.; Peng, J. Directional liquid spreading on laser textured aluminum surface. Microsyst. Technol. 2020, 26, 2767-2776. [CrossRef]

16. Xie, F.; Yang, J.; Ngo, C.-V. The effect of femtosecond laser fluence and pitches between V-shaped microgrooves on the dynamics of capillary flow. Results Phys. 2020, 19, 103606. [CrossRef]

17. Romashevskiy, S.A.; Ovchinnikov, A.V. Functional surfaces with enhanced heat transfer for spray cooling technology. High Temp. 2018, 56, 255-262. [CrossRef]

18. Singh, S.C.; ElKabbash, M.; Li, Z.; Li, X.; Regmi, B.; Madsen, M.; Jalil, S.A.; Zhan, Z.; Zhang, J.; Guo, C. Solar-trackable super-wicking black metal panel for photothermal water sanitation. Nat. Sustain. 2020, 3, 938-946. [CrossRef]

19. Bonse, J.; Gräf, S. Maxwell meets Marangoni-A review of theories on laser-induced periodic surface structures. Laser Photon. Rev. 2020, 14, 2000215. [CrossRef]

20. Bonse, J. Quo Vadis LIPSS?-Recent and future trends on laser-induced periodic surface structures. Nanomaterials 2020, 10, 1950. [CrossRef] [PubMed]

21. Ahmmed, K.M.T.; Grambow, C.; Kietzig, A.-M. Fabrication of micro/nano structures on metals by femtosecond laser micromachining. Micromachines 2014, 5, 1219-1253. [CrossRef]

22. Samanta, A.; Wang, Q.; Shaw, S.K.; Ding, H. Roles of chemistry modification for laser textured metal alloys to achieve extreme surface wetting behaviors. Mater. Des. 2020, 192, 108744. [CrossRef] 
23. Reif, J.; Varlamova, O.; Costache, F. Femtosecond laser induced nanostructure formation: Self-organization control parameters. Appl. Phys. A 2008, 92, 1019-1024. [CrossRef]

24. Reif, J.; Varlamova, O.; Ratzke, M.; Schade, M.; Leipner, H.S.; Arguirov, T. Multipulse feedback in self-organized ripples formation upon femtosecond laser ablation from silicon. Appl. Phys. A 2010, 101, 361-365. [CrossRef]

25. Reif, J.; Varlamova, O.; Uhlig, S.; Varlamov, S.; Bestehorn, M. On the physics of self-organized nanostructure formation upon femtosecond laser ablation. Appl. Phys. A 2014, 117, 179-184. [CrossRef]

26. Reif, J.; Costache, F.; Henyk, M.; Pandelov, S.V. Ripples revisited: Non-classical morphology at the bottom of femtosecond laser ablation craters in transparent dielectrics. Appl. Surf. Sci. 2002, 197-198, 891-895. [CrossRef]

27. Varlamova, O.; Reif, J.; Varlamov, S.; Bestehorn, M. The laser polarization as control parameter in the formation of laser-induced periodic surface structures: Comparison of numerical and experimental results. Appl. Surf. Sci. 2011, 257, 5465-5469. [CrossRef]

28. Makin, V.S.; Vorobyev, A.Y.; Guo, C. Dissipative nanostructures and Feigenbaum's universality in the "metal-high-power ultrashort-pulsed polarized radiation" nonequilibrium nonlinear dynamical system. Tech. Phys. Lett. 2008, 34, 387-390. [CrossRef]

29. Buividas, R.; Mikutis, M.; Juodkazis, S. Surface and bulk structuring of materials by ripples with long and short laser pulses: Recent advances. Prog. Quantum Electron. 2014, 38, 119-156. [CrossRef]

30. Vorobyev, A.Y.; Makin, V.S.; Guo, C. Periodic ordering of random surface nanostructures induced by femtosecond laser pulses on metals. J. Appl. Phys. 2007, 101, 034903. [CrossRef]

31. Förster, D.; Jäggi, B.; Michalowski, A.; Neuenschwander, B. Review on experimental and theoretical investigations of ultra-short pulsed laser ablation of metals with burst pulses. Materials 2021, 14, 3331. [CrossRef] [PubMed]

32. Florian, C.; Kirner, S.V.; Krüger, J.; Bonse, J. Surface functionalization by laser-induced periodic surface structures. J. Laser Appl. 2020, 32, 022063. [CrossRef]

33. Nivas, J.J.; Amoruso, S. Generation of supra-wavelength grooves in femtosecond laser surface structuring of silicon. Nanomaterials 2021, 11, 174. [CrossRef]

34. Gnilitskyi, I.; Derrien, T.J.-Y.; Levy, Y.; Bulgakova, N.M.; Mocek, T.; Orazi, L. High-speed manufacturing of highly regular femtosecond laser-induced periodic surface structures: Physical origin of regularity. Sci. Rep. 2017, 7, 8485. [CrossRef] [PubMed]

35. Derrien, T.J.-Y.; Krüger, J.; Itina, T.E.; Höhm, S.; Rosenfeld, A.; Bonse, J. Rippled area formed by surface plasmon polaritons upon femtosecond laser double-pulse irradiation of silicon. Opt. Express 2013, 21, 29643-29655. [CrossRef]

36. Kobayashi, T.; Wakabayashi, T.; Takushima, Y.; Yan, J. Formation behavior of laser-induced periodic surface structures on stainless tool steel in various media. Precis. Eng. 2019, 57, 244-252. [CrossRef]

37. Zhang, Y.; Jiang, Q.; Cao, K.; Chen, T.; Cheng, K.; Zhang, S.; Feng, D.; Jia, T.; Sun, Z.; Qiu, J. Extremely regular periodic surface structures in a large area efficiently induced on silicon by temporally shaped femtosecond laser. Photon. Res. 2021, 9, 839-847. [CrossRef]

38. Müller, F.A.; Kunz, C.; Gräf, S. Bio-inspired functional surfaces based on laser-induced periodic surface structures. Materials 2016, 9, 476. [CrossRef]

39. Rudenko, A.; Colombier, J.-P.; Höhm, S.; Rosenfeld, A.; Krüger, J.; Bonse, J.; Itina, T.E. Spontaneous periodic ordering on the surface and in the bulk of dielectrics irradiated by ultrafast laser: A shared electromagnetic origin. Sci. Rep. 2017, 7, 12306. [CrossRef]

40. Colombier, J.-P.; Rudenko, A.; Silaeva, E.; Zhang, H.; Sedao, X.; Bévillon, E.; Reynaud, S.; Maurice, C.; Pigeon, F.; Garrelie, F.; et al. Mixing periodic topographies and structural patterns on silicon surfaces mediated by ultrafast photoexcited charge carriers. Phys. Rev. Res. 2020, 2, 043080. [CrossRef]

41. Pan, A.F.; Wang, W.J.; Mei, X.S.; Yang, H.Z.; Sun, X.F. The formation mechanism and evolution of ps-laser-induced high-spatialfrequency periodic surface structures on titanium. Appl. Phys. A 2017, 123, 21. [CrossRef]

42. Vorobyev, A.Y.; Guo, C. Colorizing metals with femtosecond laser pulses. Appl. Phys. Lett. 2008, 92, 041914. [CrossRef]

43. Vorobyev, A.Y.; Makin, V.S.; Guo, C. Brighter light sources from black metal: Significant increase in emission efficiency of incandescent light sources. Phys. Rev. Lett. 2009, 102, 234301. [CrossRef] [PubMed]

44. Dusser, B.; Sagan, S.; Soder, H.; Faure, N.; Colombier, J.-P.; Jourlin, M.; Audouard, E. Controlled nanostructrures formation by ultra fast laser pulses for color marking. Opt. Express 2010, 18, 2913-2924. [CrossRef] [PubMed]

45. Ionin, A.A.; Klimachev, Y.M.; Kozlov, A.Y.; Kudryashov, S.I.; Ligachev, A.E.; Makarov, S.V.; Seleznev, L.V.; Sinitsyn, D.V.; Rudenko, A.A.; Khmelnitsky, R.A. Direct femtosecond laser fabrication of antireflective layer on GaAs surface. Appl. Phys. A 2013, 111, 419-423. [CrossRef]

46. Zhang, D.; Ranjan, B.; Tanaka, T.; Sugioka, K. Multiscale hierarchical micro/nanostructures created by femtosecond laser ablation in liquids for polarization-dependent broadband antireflection. Nanomaterials 2020, 10, 1573. [CrossRef] [PubMed]

47. Maragkaki, S.; Skaradzinski, C.A.; Nett, R.; Gurevich, E. Influence of defects on structural colours generated by laser-induced ripples. Sci. Rep. 2020, 10, 53. [CrossRef]

48. Arul, R.; Dong, J.; Simpson, M.C.; Gao, W. LIPSS-sticks: Laser induced double self organization enhances the broadband light absorption of $\mathrm{TiO}_{2}$ nanotube arrays. Adv. Photon. Res. 2021, 2, 2000133. [CrossRef]

49. Liu, H.; Lin, W.; Hong, M. Surface coloring by laser irradiation of solid substrates. APL Photon. 2019, 4, 051101. [CrossRef]

50. Jwad, T.; Penchev, P.; Nasrollahi, V.; Dimov, S. Laser induced ripples' gratings with angular periodicity for fabrication of diffraction holograms. Appl. Surf. Sci. 2018, 453, 449-456. [CrossRef] 
51. Guay, J.-M.; Lesina, A.C.; Baxter, J.; Killaire, G.; Ramunno, L.; Berini, P.; Weck, A. Topography tuning for plasmonic color enhancement via picosecond laser bursts. Adv. Opt. Mater. 2018, 6, 1800189. [CrossRef]

52. Fraggelakis, F.; Mincuzzi, G.; Manek-Hönninger, I.; Lopez, J.; Kling, R. Generation of micro- and nano-morphologies on a stainless steel surface irradiated with $257 \mathrm{~nm}$ femtosecond laser pulses. RSC Adv. 2018, 8, 16082-16087. [CrossRef]

53. Allahyari, E.; Nivas, J.J.; Oscurato, S.L.; Salvatore, M.; Ausanio, G.; Vecchione, A.; Fittipaldi, R.; Maddalena, P.; Bruzzese, R.; Amoruso, S. Laser surface texturing of copper and variation of the wetting response with the laser pulse fluence. Appl. Surf. Sci. 2019, 470, 817-824. [CrossRef]

54. Martínez-Calderon, M.; Rodriguez, A.; Ponte, A.D.; Morant-Miñana, M.C.; Gomez-Aranzadi, M.; Olaizola, S. Femtosecond laser fabrication of highly hydrophobic stainless steel surface with hierarchical structures fabricated by combining ordered microstructures and LIPSS. Appl. Surf. Sci. 2016, 374, 81-89. [CrossRef]

55. Vorobyev, A.; Guo, C. Femtosecond laser structuring of titanium implants. Appl. Surf. Sci. 2007, 253, 7272-7280. [CrossRef]

56. Epperlein, N.; Menzel, F.; Schwibbert, K.; Koter, R.; Bonse, J.; Sameith, J.; Krüger, J.; Toepel, J. Influence of femtosecond laser produced nanostructures on biofilm growth on steel. Appl. Surf. Sci. 2017, 418, 420-424. [CrossRef]

57. Cunha, A.; Elie, A.-M.; Plawinski, L.; Serro, A.; Rego, A.M.B.D.; Almeida, A.; Urdaci, M.C.; Durrieu, M.-C.; Vilar, R. Femtosecond laser surface texturing of titanium as a method to reduce the adhesion of Staphylococcus aureus and biofilm formation. Appl. Surf. Sci. 2016, 360, 485-493. [CrossRef]

58. Heitz, J.; Plamadeala, C.; Muck, M.; Armbruster, O.; Baumgartner, W.; Weth, A.; Steinwender, C.; Blessberger, H.; Kellermair, J.; Kirner, S.V.; et al. Femtosecond laser-induced microstructures on Ti substrates for reduced cell adhesion. Appl. Phys. A 2017, 123, 734. [CrossRef]

59. Lange, K.; Schulz-Ruhtenberg, M.; Caro, J. Platinum electrodes for oxygen reduction catalysis designed by ultrashort pulse laser structuring. ChemElectroChem 2017, 4, 570-576. [CrossRef]

60. Bonse, J.; Kirner, S.; Koter, R.; Pentzien, S.; Spaltmann, D.; Krüger, J. Femtosecond laser-induced periodic surface structures on titanium nitride coatings for tribological applications. Appl. Surf. Sci. 2017, 418, 572-579. [CrossRef]

61. Cubero, Á.; Martínez, E.; Angurel, L.A.; De La Fuente, G.F.; Navarro, R.; Legall, H.; Krüger, J.; Bonse, J. Surface superconductivity changes of niobium sheets by femtosecond laser-induced periodic nanostructures. Nanomaterials 2020, 10, 2525. [CrossRef]

62. Nivas, J.; Valadan, M.; Salvatore, M.; Fittipaldi, R.; Himmerlich, M.; Rimoldi, M.; Passarelli, A.; Allahyari, E.; Oscurato, S.; Vecchione, A.; et al. Secondary electron yield reduction by femtosecond pulse laser-induced periodic surface structuring. Surf. Interfaces 2021, 25, 101179. [CrossRef]

63. Parellada-Monreal, L.; Castro-Hurtado, I.; Martínez-Calderón, M.; Presmanes, L.; Mandayo, G. Laser-induced periodic surface structures on $\mathrm{ZnO}$ thin film for high response $\mathrm{NO}_{2}$ detection. Appl. Surf. Sci. 2019, 476, 569-575. [CrossRef]

64. Fang, R.; Li, Z.; Zhang, X.; Zhu, X.; Zhang, H.; Li, J.; Pan, Z.; Huang, Z.; Yang, C.; Zheng, J.; et al. Spreading and drying dynamics of water drop on hot surface of superwicking Ti-6Al-4V alloy material fabricated by femtosecond laser. Nanomaterials 2021, 11, 899. [CrossRef] [PubMed]

65. Bar-Cohen, A.; Geisler, K.J.L. Cooling the electronic brain. Mech. Eng. 2011, 133, 38-41. [CrossRef]

66. Nadjahi, C.; Louahlia, H.; Lemasson, S. A review of thermal management and innovative cooling strategies for data center. Sustain. Comput. Inform. Syst. 2018, 19, 14-28. [CrossRef]

67. Han, Z.; Sun, X.; Wei, H.; Ji, Q.; Xue, D. Energy saving analysis of evaporative cooling composite air conditioning system for data centers. Appl. Therm. Eng. 2021, 186, 116506. [CrossRef]

68. Erickson, D.; Sinton, D.; Psaltis, D. Optofluidics for energy applications. Nat. Photon. 2011, 5, 583-590. [CrossRef]

69. Sevinchan, E.; Dincer, I.; Lang, H. A review on thermal management methods for robots. Appl. Therm. Eng. 2018, 140, 799-813. [CrossRef]

70. Tariq, R.; Sheikh, N.; Xamán, J.; Bassam, A. An innovative air saturator for humidification-dehumidification desalination application. Appl. Energy 2018, 228, 789-807. [CrossRef]

71. Ouyang, T.; Su, Z.; Yang, R.; Li, C.; Huang, H.; Wei, Q. A framework for evaluating and optimizing the cascade utilization of medium-low grade waste heat in marine dual-fuel engines. J. Clean. Prod. 2020, 276, 123289. [CrossRef]

72. Brough, D.; Ramos, J.; Delpech, B.; Jouhara, H. Development and validation of a TRNSYS type to simulate heat pipe heat exchangers in transient applications of waste heat recovery. Int. J. Thermofluids 2021, 9, 100056. [CrossRef]

73. Aono, Y.; Watanabe, N.; Ueno, A.; Nagano, H. Development of a loop heat pipe with kW-class heat transport capability. Appl. Therm. Eng. 2021, 183, 116169. [CrossRef]

74. Shukla, K.N. Heat pipe for aerospace applications-An overview. J. Electron. Cool. Therm. Control. 2015, 5, 55065. [CrossRef]

75. Zhang, H.; Li, G.; Chen, L.; Man, G.; Miao, J.; Ren, X.; He, J.; Huo, Y. Development of flat-plate loop heat pipes for spacecraft thermal control. Microgravity Sci. Technol. 2019, 31, 435-443. [CrossRef]

76. Mahmood, M.H.; Sultan, M.; Miyazaki, T.; Koyama, S.; Maisotsenko, V.S. Overview of the Maisotsenko cycle-A way towards dew point evaporative cooling. Renew. Sustain. Energy Rev. 2016, 66, 537-555. [CrossRef]

77. Fan, X.; Lu, X.; Nie, H.; Zhu, H.; Wang, Q.; Kang, Y.; Liu, S.; Zheng, X.; Liu, Z.; Zhang, Y.; et al. An experimental study of a novel dew point evaporative cooling tower based on M-cycle. Appl. Therm. Eng. 2021, 190, 116839. [CrossRef]

78. Dizaji, H.S.; Hu, E.J.; Chen, L.; Pourhedayat, S. Comprehensive exergetic study of regenerative Maisotsenko air cooler; formulation and sensitivity analysis. Appl. Therm. Eng. 2019, 152, 455-467. [CrossRef] 
79. Zanchini, E.; Naldi, C. Energy saving obtainable by applying a commercially available M-cycle evaporative cooling system to the air conditioning of an office building in North Italy. Energy 2019, 179, 975-988. [CrossRef]

80. Min, J.; Webb, R.L. Long-term wetting and corrosion characteristics of hot water treated aluminum and copper fin stocks. Int. J. Refrig. 2002, 25, 1054-1061. [CrossRef]

81. Bang, S.; Ryu, S.; Ki, S.; Song, K.; Kim, J.; Kim, J.; Nam, Y. Superhydrophilic catenoidal aluminum micropost evaporator wicks. Int. J. Heat Mass Transf. 2020, 158, 120011. [CrossRef]

82. Godinez, J.; Fadda, D.; Lee, J.; You, S.M. Development of a stable Boehmite layer on aluminum surfaces for improved pool boiling heat transfer in water. Appl. Therm. Eng. 2019, 156, 541-549. [CrossRef]

83. Wang, X.; Fadda, D.; Godinez, J.C.; Lee, J.; You, S.M. Capillary evaporation of water from aluminum high-temperature conductive microporous coating. Int. J. Heat Mass Transf. 2020, 153, 119660. [CrossRef]

84. Abgrall, P.; Gué, A.-M. Lab-on-chip technologies: Making a microfluidic network and coupling it into a complete microsystem-a review. J. Micromech. Microeng. 2007, 17, R15-R49. [CrossRef]

85. Fang, R.; Zhu, H.; Li, Z.; Zhu, X.; Zhang, X.; Huang, Z.; Li, K.; Yan, W.; Huang, Y.; Maisotsenko, V.S.; et al. Temperature effect on capillary flow dynamics in 1D array of open nanotextured microchannels produced by femtosecond laser on silicon. Nanomaterials 2020, 10, 796. [CrossRef]

86. Bailey, A.W.; Modak, A. Numerical simulation of laser ablation with cavity reflections. J. Thermophys. Heat Transf. 1989, 3, 42-45. [CrossRef]

87. Torkamany, M.; Ghaini, F.M.; Poursalehi, R. An insight to the mechanism of weld penetration in dissimilar pulsed laser welding of niobium and Ti-6Al-4V. Opt. Laser Technol. 2016, 79, 100-107. [CrossRef]

88. Banks, P.; Feit, M.; Rubenchik, A.; Stuart, B.; Perry, M. Material effects in ultra-short pulse laser drilling of metals. Appl. Phys. A 1999, 69, S377-S380. [CrossRef]

89. Vorobyev, A.Y.; Guo, C. Reflection of femtosecond laser light in multipulse ablation of metals. J. Appl. Phys. 2011, 110, 043102. [CrossRef]

90. Robertson, S.M.; Kaplan, A.F.; Frostevarg, J. Material ejection attempts during laser keyhole welding. J. Manuf. Process. 2021, 67, 91-100. [CrossRef]

91. Hwang, T.Y.; Guo, C. Angular effects of nanostructure-covered femtosecond laser induced periodic surface structures on metals. J. Appl. Phys. 2010, 108, 073523. [CrossRef]

92. Fuentes-Edfuf, Y.; Sánchez-Gil, J.A.; Florian, C.; Giannini, V.; Solis, J.; Siegel, J. Surface plasmon polaritons on rough metal surfaces: Role in the formation of laser-induced periodic surface structures. ACS Omega 2019, 4, 6939-6946. [CrossRef]

93. Florian, C.; Déziel, J.-L.; Kirner, S.; Siegel, J.; Bonse, J. The role of the laser-induced oxide layer in the formation of laser-induced periodic surface structures. Nanomaterials 2020, 10, 147. [CrossRef] [PubMed]

94. Vorobyev, A.Y.; Guo, C. Nanochemical effects in femtosecond laser ablation of metals. Appl. Phys. Lett. 2013, 102, 074107. [CrossRef]

95. Stange, M.; Dreyer, M.E.; Rath, H.J. Capillary driven flow in circular cylindrical tubes. Phys. Fluids 2003, 15, 2587-2601. [CrossRef]

96. Das, S.; Waghmare, P.R.; Mitra, S.K. Early regimes of capillary filling. Phys. Rev. E 2012, 86, 067301. [CrossRef]

97. Huang, W.; Liu, Q.; Li, Y. Capillary filling flows inside patterned-surface microchannels. Chem. Eng. Technol. 2006, 29, 716-723. [CrossRef]

98. Quéré, D. Inertial capillarity. EPL 1997, 39, 533-538. [CrossRef]

99. Andrukh, T.; Monaenkova, D.; Rubin, B.; Lee, W.-K.; Kornev, K.G. Meniscus formation in a capillary and the role of contact line friction. Soft Matter 2014, 10, 609-615. [CrossRef]

100. Fang, R.; Zhu, H.; Li, Z.; Yan, W.; Zhang, X.; Zhu, X.; Maisotsenko, V.S.; Vorobyev, A.Y. Capillary Nylon 6 polymer material produced by femtosecond laser processing. Opt. Express 2019, 27, 36066-36074. [CrossRef]

101. Fries, N.; Dreyer, M. The transition from inertial to viscous flow in capillary rise. J. Colloid Interface Sci. 2008, 327, 125-128. [CrossRef] [PubMed]

102. Lade, R.K.; Jochem, K.S.; Macosko, C.W.; Francis, L.F. Capillary coatings: Flow and drying dynamics in open microchannels. Langmuir 2018, 34, 7624-7639. [CrossRef]

103. Duan, Z.; Zhao, X.; Zhan, C.; Dong, X.; Chen, H. Energy saving potential of a counter-flow regenerative evaporative cooler for various climates of China: Experiment-based evaluation. Energy Build. 2017, 148, 199-210. [CrossRef]

104. Xu, P.; Ma, X.; Zhao, X.; Xiong, Y.; Sun, Y. Feasibility analysis for a novel dew point air cooler applied in warm and humid climate: A case study in Beijing. Energy Procedia 2019, 158, 2126-2131. [CrossRef]

105. Cho, H.-J.; Preston, D.J.; Zhu, Y.; Wang, E.N. Nanoengineered materials for liquid-vapour phase-change heat transfer. Nat. Rev. Mater. 2017, 2, 16092. [CrossRef]

106. Vaartstra, G.; Zhang, L.; Lu, Z.; Díaz-Marín, C.D.; Grossman, J.C.; Wang, E.N. Capillary-fed, thin film evaporation devices. J. Appl. Phys. 2020, 128, 130901. [CrossRef]

107. Washburn, E.W. The dynamics of capillary flow. Phys. Rev. 1921, 17, 273-283. [CrossRef]

108. Yang, M.; Cao, B.; Wang, W.; Yun, H.-M.; Chen, B.-M. Experimental study on capillary filling in nanochannels. Chem. Phys. Lett. 2016, 662, 137-140. [CrossRef]

109. Rye, R.R.; Mann, J.J.A.; Yost, F.G. The flow of liquids in surface grooves. Langmuir 1996, 12, 555-565. [CrossRef] 
110. Tian, J.; Kannangara, D.; Li, X.; Shen, W. Capillary driven low-cost V-groove microfluidic device with high sample transport efficiency. Lab Chip 2010, 10, 2258-2264. [CrossRef] [PubMed]

111. Deng, D.; Tang, Y.; Zeng, J.; Yang, S.; Shao, H. Characterization of capillary rise dynamics in parallel micro V-grooves. Int. J. Heat Mass Transf. 2014, 77, 311-320. [CrossRef]

112. Bico, J.; Tordeux, C.; Quéré, D. Rough wetting. EPL 2001, 55, 214-220. [CrossRef]

113. Kim, S.J.; Moon, M.-W.; Lee, K.-R.; Lee, D.-Y.; Chang, Y.S.; Kim, H.-Y. Liquid spreading on superhydrophilic micropillar arrays. J. Fluid Mech. 2011, 680, 477-487. [CrossRef]

114. Lade, J.R.K.; Hippchen, E.J.; Macosko, C.W.; Francis, L.F. Dynamics of capillary-driven flow in 3D printed open microchannels. Langmuir 2017, 33, 2949-2964. [CrossRef] [PubMed]

115. Bernardin, J.D.; Mudawar, I.; Walsh, C.B.; Franses, E.I. Contact angle temperature dependence for water droplets on practical aluminum surfaces. Int. J. Heat Mass Transf. 1997, 40, 1017-1033. [CrossRef]

116. Drelich, J.; Chibowski, E. Superhydrophilic and superwetting surfaces: Definition and mechanisms of control. Langmuir 2010, 26, 18621-18623. [CrossRef]

117. Vorobyev, A.Y.; Guo, C. Multifunctional surfaces produced by femtosecond laser pulses. J. Appl. Phys. 2015, 117, 033103. [CrossRef]

118. Dhillon, N.S.; Buongiorno, J.; Varanasi, K.K. Critical heat flux maxima during boiling crisis on textured surfaces. Nat. Commun. 2015, 6, 8247. [CrossRef]

119. Chu, K.-H.; Joung, Y.S.; Enright, R.; Buie, C.R.; Wang, E.N. Hierarchically structured surfaces for boiling critical heat flux enhancement. Appl. Phys. Lett. 2013, 102, 151602. [CrossRef]

120. Chen, L.; Shen, J.; Ge, Y.; Wu, Z.; Wang, W.; Zhu, F.; Feng, H. Power and efficiency optimization of open Maisotsenko-Brayton cycle and performance comparison with traditional open regenerated Brayton cycle. Energy Convers. Manag. 2020, $217,113001$. [CrossRef]

121. Guangya, Z.; Chow, T.; Fong, K.; Lee, C. Investigation on humidified gas turbine cycles with Maisotsenko-cycle-based air saturator. Energy Procedia 2019, 158, 5195-5200. [CrossRef]

122. Saghafifar, M.; Gadalla, M. Analysis of Maisotsenko open gas turbine power cycle with a detailed air saturator model. Appl. Energy 2015, 149, 338-353. [CrossRef] 